\title{
Conservation Survey, Condition Report and Collections Care Proposal for the World War I Portrait Collection at State Records of South Australia
}

By: Sarah Ann Ernisse

B.A., Communications: Visual Media, American University, 2006

A thesis project presented to Ryerson University and

George Eastman House International Museum of Photography and Film

in partial fulfillment of the requirements for the degree of

Master of the Arts in the program of

Photographic Preservation and Collections Management Toronto, Ontario, Canada, 2008

(C) Sarah Ann Ernisse, 2008 


\section{Author's Declaration}

I hereby declare that I am the sole author of this thesis project. I authorize Ryerson University and George Eastman House International Museum of Photography and Film to lend this thesis project to other institutions or individuals for the purpose of scholarly research.

I further authorize Ryerson University and George Eastman House International Museum of Photography and Film to reproduce this thesis project by photocopying or by other means, in total or in part, at the request of other institutions or individuals for the purpose of scholarly research. 


\section{Acknowledgements}

I would not have been able to complete this thesis without the guidance and help from the enthusiastic staff at State Records of South Australia. I would especially like to thank Lee McElroy, Senior Archivist, Michael Fidler, Repository Manager and Matthew GordonClark, Team Leader, from State Records for their additional assistance. I also thank my thesis advisor, Alison Nordström, for her help with the written portion of this thesis and Robert Burley for acting as second reader. For their advice and expertise, I would like to thank Grant B. Romer and Ralph Wiegandt from the Conservation Department at George Eastman House, Doug Nishimura from Image Permanence Institute and Luisa Casella from the Mellon Advanced Residency Program. This thesis would not have been possible without the support of my research assistant and fiancé, Shannon Mason, who sent me preliminary information on the collection for proposals and orals and to Matthew Ernisse, my brother, who wrote the computer program to generate a random sample for the condition report.

Sarah Ernisse, 2008 


\begin{abstract}
Conservation Survey, Condition Report and Collections Care Proposal for the World War I Portrait Collection at State Records of South Australia, Master of the Arts, 2008, Sarah Ann Ernisse, Photographic Preservation and Collections Management, Ryerson University

This practical thesis project report contains a conservation survey, condition report and collections care proposal for the World War I portrait collection held at State Records of South Australia. The plan prescribes immediate, short term and long term recommendations for the improvement of preservation techniques for the World War I collection. The paper also contains information and results gathered through the condition report of the collection sample and conservation survey. The survey investigated the current environment and storage facilities, access, security and disaster planning surrounding the collection.

The paper also outlines the practices and methodologies of this applied thesis for both the conservation survey and condition report. The collection care proposal assesses current practices in order to provide State Records with accurate goals that offer flexible options. A detailed list of housing recommendations is included in the proposal; an advantages and disadvantages assessment is included for each option to help State Records better fit its needs and abilities in the future. Charts showing the results of the condition report and environmental assessment from the conservation survey are included in the appendix for further reference. This project is intended to draw attention to the urgent need for better preservation practices for the World War I portrait collection.
\end{abstract}




\section{Contents}

1 Introduction 1

2 Methodology "4 4

Choosing the Sample . . . . . . . . . . . . . . . . . . . . 4

Layout of the Condition Report . . . . . . . . . . . . . . . . 6

Conducting a Conservation Survey $\ldots \ldots \ldots \ldots$. . . . . . . 7

3 Institutional History $\quad 10$

History and Structure of State Records . . . . . . . . . . . . . . 10

Under the State Records Act $1997 \ldots \ldots \ldots$

State Records and the World War I Portrait Collection . . . . . . . . . . . . . 12

4 Collection History and Access $\quad 14$

Photographs of Soldiers from the Great War, $1918-1952 \ldots \ldots \ldots$. . . . . 14

Current Arrangement and Housing of the Collection . . . . . . . . . . . . . . 15

Indexes, Finding Aids and Web Catalogue $\ldots \ldots \ldots \ldots . \ldots \ldots$

Research and Access . . . . . . . . . . . . . . . . . . . . . . 19

5 Condition of the Collection $\quad 21$

Results from the Condition Report . . . . . . . . . . . . . . . . . 21

Influence of Current Housing . . . . . . . . . . . . . . . . . . . 22 
6 Repository and Environment Assessment 24

Repository Design ... . . . . . . . . . . . . . . . . . 24

Temperature and Relatively Humidity . . . . . . . . . . . . . . . . 26

Air Quality . . . . . . . . . . . . . . . . . . . 27

Film-Based Materials and other Issues $\ldots \ldots \ldots . . \ldots . . \ldots 27$

7 Emergency Planning and Security 30

Emergency Disaster Plans and Preparedness . . . . . . . . . . . . . . . . . . 30

Security at State Records . . . . . . . . . . . . . . . . . . . . 32

8 Collections Care Proposal 33

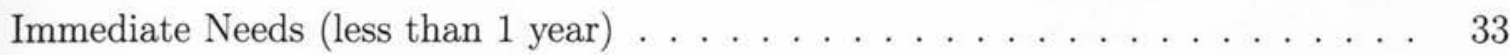

Short Term Goals $($ maximum $3-5$ years $) \quad \ldots \ldots \ldots \ldots$. . . . . . . . 35

Four Housing Proposals . . . . . . . . . . . . . . . . . . . . . . 37

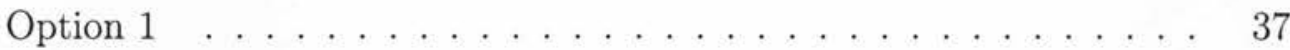

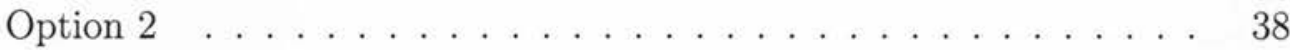

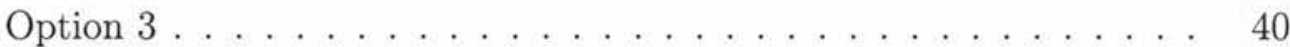

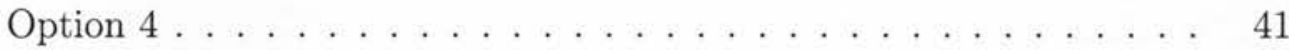

Housing Cost Analysis and Advantages/Disadvantages Assessment Tables . . . . . . . . . . . . . . . . 43

Long Term Goals $(5+$ years $) \ldots \ldots$. . . . . . . . . . . . . . . . . 43

9 Conclusion $\quad 45$

$\begin{array}{ll}\text { Bibliography } & 47\end{array}$

A Call for Donations Poster, $1918 \quad 49$

B Call for Donations Circular, $1918 \quad 50$ 
C Examples from GRG26/5/4

D GRG26/5/4/1370 and Examples of Letters Included

E Chart of Retrieval Requests from 2004 to 2008

F Chart of Photographic Formats Found in the Sample

G Charts Showing Most Common Types of Deterioration by Box

H Chart of Most Common Types of Deterioration Found Throughout the Overall Sample

I Chart of Most Common Types of Deterioration Found in the Particulars Sheets

J Environmental Report Charts 68 


\section{List of Figures}

4.1 Intimate Enclosure . . . . . . . . . . . . . . . . . . 17

4.2 Box from the Collection $\ldots \ldots \ldots \ldots \ldots$

4.3 Use of Linen String . . . . . . . . . . . . . . . . . . . . . . . . 18

4.4 Contemporary Index $\ldots \ldots \ldots \ldots$

4.5 Retrieval Slip . . . . . . . . . . . . . . . . . . . . . . 20

5.1 Damaged Intimate Enclosure . . . . . . . . . . . . . . . . . . . . 23

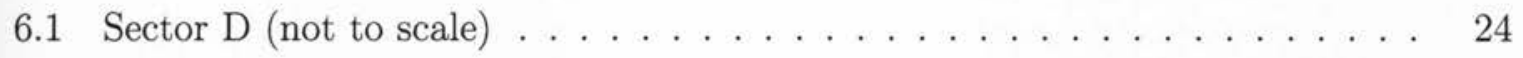

6.2 WWI Collection in Sector D . . . . . . . . . . . . . . . . 25

6.3 Film Storage in Sector D . . . . . . . . . . . . . . . . . 28

6.4 Example of Film Containers . . . . . . . . . . . . . . . . . 28

7.1 Fire Hose $\ldots \ldots \ldots \ldots \ldots$

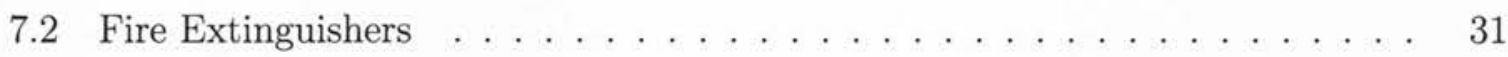




\section{List of Tables}

2.1 Sampling Bins . . . . . . . . . . . . . . . . . . . . . . 6

8.1 Housing Cost Analysis . . . . . . . . . . . . . . . . . . . 43

8.2 Advantages/Disadvantages Assessment . . . . . . . . . . . . . . 43 


\section{Chapter 1}

\section{Introduction}

State Records of South Australia is the state archive for all permanent government records as outlined under the State Records Act 1997. It is custodian to over 75 kilometres of government records, which encompass a wide variety of formats, including pictorial material. In its Gepps Cross repository, it houses a collection of photographs of soldiers, sailors and nurses who served in the Australian Imperial Forces during World War I. These privately donated photographs are accompanied by a particulars sheet that gives the name, date of birth, enlistment date, trade, rank, number, battalion and other important information about the subject and donor. There are approximately 2,960 photographs in this collection that remain in original housing and arrangement; they were collected from 1918 until 1952 by the Public Library, Art Gallery and Museum of South Australia. This collection of photographs is a unique and irreplaceable document of those from South Australia who served in the Australian Imperial Forces during the First World War. It endures as a valuable resource to family historians and World War I scholars. Therefore, the continued preservation of the collection is not only part of State Records's objectives and responsibilities under the State Records Act 1997, but also vital if the collection is to survive for future generations of researchers.

To ensure the preservation of this collection, I developed a collections care plan that recommended solid immediate, short term and long term goals to improve the preservation of the collection over the next ten years. A conservation survey and a condition survey of the collection were conducted in order to write recommendations particular to the collection at State Records. The conservation survey is an assessment of policies, practices and conditions that have an "impact on the care and preservation of the collection." ${ }^{\text {This includes }}$ reviewing environmental and storage conditions, security, emergency planning, history and policy of both State Records and the collection. Combined with the conservation survey is a condition report of the collection that reviews the present state of objects within the collection. By conducting a condition report of a statistically significant sample of the collection,

\footnotetext{
${ }^{1}$ Sara Wolf. "The Conservation Assessment: A Tool for Planning, Implementing, and Fund-raising," (Conservation Assessment Program, 1998), https://www.hertitagepreservation.org/PDFS/2002year (assessed April 6, 2008), 2.
} 
accurate information about the condition of the collection can be gathered and assessed to rank the severity of different kinds of deterioration. These findings from the condition report can be paired with the conservation survey to analyse the possible causes of deterioration in order to create an effective collections care plan.

The report from the condition survey revealed that the main types of deterioration found in the part of the collection sampled were abrasion, silver mirroring, fading and grime/dirt or markings. Excessive handling causes many of those types of deterioration. The current opaque brown bag enclosures used throughout the collection require excessive handling in order to remove the photograph for viewing, leaving room for potential abrasion and other physical damage, such as the accumulation of dirt, grime or other marks. The silver mirroring was most likely caused by relative humidity fluctuations or air pollutants over time since silver mirroring is caused when silver oxidizes, creating new compounds; the silver begins to fade and if the excess silver is re-deposited at the surface of the gelatin, a bluish sheen or silver mirroring begins to develop. ${ }^{2}$ The general problem of fading in the collection can be attributed to the possible poor processing of some of the photographs, oxidation from air pollutants, light exposure and high relative humidity and/or temperature. It is important that in the environment, a low relative humidity is maintained as well as the air filtered to rid the repository of harmful pollutants. However, it is important to keep in mind that the photographs have aged over ninety years and in most cases, time will cause both fading and silver mirroring on many gelatin silver photographs.

The condition report of the collection also considered the particulars sheets included with each photograph. The two most common forms of deterioration occurring in the particulars sheets were embrittlement of the paper and fading of the inks used to fill in the sheets. This finding was expected because of the mechanical pulping process used to make most papers in the 20th century, which would leave a high lignin content; over time the lignin would become highly acidic, leaving the paper yellow and embrittled. Also, inks used around the early 20 th century often contained iron gall ink, which is acidic; over time it would fade to varying shades of brown and eventually burn through paper. ${ }^{3}$

The findings of the conservation survey show that staff in both the repository and research centre take care in ensuring that the records remain at State Records and that security measures are also taken to protect against damage from handling by researchers. These steps prevent unnecessary damage and deterioration of the object. The emergency disaster plan also proved to be extremely detailed and careful, outlining all the possible disasters, from small to large. The repository itself was for the most part in good order with proper emergency fire systems and exits. However, roof leakage for the past few years creates a possible water damage issue and should be monitored. As Sector D is enclosed with a drop ceiling, there is an added layer to protect against water damage, aside from the metal shelving units; though note should be taken that the current boxes the WWI collection is

\footnotetext{
${ }^{2}$ Reilly et al., "Photograph Preservation and the Research Library," (Mountain View: The Research Libraries Group, 1991), 12.

${ }^{3}$ Craig Tuttle, "An Ounce of Preservation: A Guide to the Care of Papers and Photographs," (Highland city: Rainbow Books, 1995), 20.
} 
housed in are not waterproof. The temperature and relative humidity of the collection are within suitable ranges for the WWI collection and should continue to be monitored and maintained. The only concern about the environment is the air filtration system, since no information was available about the purification for gaseous particles or how frequently the room was purified. Since the repository is located both on a heavy trucking route and in an industrial area, a good purification system is essential to prevent harmful pollutants from accelerating the deterioration of the collection.

Based on my findings in both the condition report and conservation survey, I created a collections care proposal that outlined immediate, short term and long term goals to ensure the future preservation of the collection at State Records of South Australia. This proposal claims the immediate goals as recommendations that are important enough to be put into action as soon as possible. The recommendations regarding the future preservation of the WWI collection at State Records are:

Immediate (less than 1 year)

- The War Memorial in Canberra should be notified about the existence and details of the WWI collection.

- Make an assessment of the current air filtration systems in Sector D.

. Identify and assess all the film currently stored in Sector D.

Short Term (3-5 years)

- The arrangement should be assessed and plans implemented for the rearrangement of the collection.

- The photographs in the WWI collection should be re-housed in order to protect the objects against deterioration. Four possible housing options are included.

Long Term (5+ years)

- The WWI collection should undergo digitisation in order to add digital images to the web catalogue.

- The web catalogue should be assessed for completeness.

The recommendations are explained in further detail in the collections care proposal that outlines possible methods for carrying out some of the recommendations. These recommendations have been carefully designed after looking at the current condition of the collection and facilities. State Records has a responsibility to look after this collection and ensure its care and preservation. This survey and proposal have gathered strong evidence that calls for the improvement of the preservation techniques of these unique and irreplaceable photographs. 


\section{Chapter 2}

\section{Methodology}

\section{Choosing the Sample}

Conducting a condition report of the entire collection would have been too time consuming for me to complete with 2,960 records in the collection and only a few weeks in South Australia. Even if there was enough time to survey the condition of each record, it is unlikely that any institution would have the resources to survey all 2,960 records. Taking a statistically significant sample of the collection would reduce how much time I spent on the condition report, while still returning accurate results; institutions also use statistical sampling when assessing the condition of its holdings. Therefore, I chose to select a random sample of the collection; this was a reasonable option since the entire collection is made of gelatin silver, black and white prints and no other photographic medium. Taking a random sample of the collection would also give me a sample that ideally came closest to representing the overall collection. This is important when it comes to analysing the data and applying it to the collection as a whole.

After consulting Doug Nishimura from the Image Permanence Institute, I decided on three possible methods by which to choose a sample size. ${ }^{1}$ The first method came from National Bureau of Standards in the 1960s. It suggested to sample either $0.1 \%$ of the collection or 100 items - whichever one was larger. In the case of the WWI portrait collection with 2,960 photographs, 100 photographs would be larger than sampling $0.1 \%$ of the collection. However, the problem with this method is that the sample size is far too small to be statistically significant. In the case of this project, I wanted at least a $95 \%$ confidence level, with a $+/-$ $3 \%$ error. This means that if I sampled the same collection 100 times, 95 of those times would produce the same results, within the $+/-3 \%$ error. In order to be that confident, I would have to look at far more photographs than 100 . The second possible method came from a journal for librarians, which would allow me to sample for a $95 \%$ confidence level. It

\footnotetext{
${ }^{1}$ The information on sampling, including the following formulas, comes from an e-mail from Doug Nishimura on 18 April 2008.
} 
assumes the population is infinite and leaves me with a sample of over 1,000 photographs, which is over $1 / 3$ of the collection. The formula looked like:

$$
N=p(1-p)(z / E)^{2}
$$

While statistically significant, the sample size is too large to survey in a reasonable time. The third method allowed me to sample for a $95 \%$ confidence level, but also allowed me to select a random sample smaller than over 1,000 photographs. The third method assumes that I am sampling without replacement, which means that the probability of my next draw depends on the draw before. The formula for the third method looks like:

$$
n=\frac{N z^{2} p q}{E^{2}(N-1)+z^{2} p q}
$$

$$
\begin{aligned}
& \text { Nomenclature } \\
& E=\text { Error } \\
& N=\text { Population } \\
& n=\text { Sample size } \\
& \mathrm{p}=\text { Fraction of population without problem } \\
& q=1-p \\
& z=\text { Critical standard normal value }
\end{aligned}
$$

In the case of $p$, since this is my first sample, I must assume the worst case scenario is $50 \%$ or 0.5 . In order to have a $95 \%$ confidence level with $+/-3 \%$ error, $z$, the critical standard value must be 1.96 . With these values inserted into the third formula, the sample size is 785 photographs or $26.5 \%$ of the collection. This is far smaller than the over 1,000 photographs from the second method and unlike the first method, this one is statistically significant.

Before using a random sample generator to gather the accession numbers, I decided to use proportionately stratified sampling in order to break up the collection by the thirteen boxes it is stored in. This puts the number of photographs from each box into sampling bins and then chooses a portion of the sample based on the percentage of the collection represented in that box. Table 2.1 shows the breakdown of the photographs per box, the percentage of the collection that is represented in each and the number from the sample pulled from that box. 
Table 2.1: Sampling Bins

\begin{tabular}{ccc}
\hline Box \# & \% of collection & Sample needed \\
\hline 1 & 8.75 & 69 \\
2 & 8.11 & 64 \\
3 & 7.43 & 58 \\
4 & 8.45 & 66 \\
5 & 7.77 & 61 \\
6 & 7.8 & 61 \\
7 & 8.07 & 63 \\
8 & 7.8 & 61 \\
9 & 8.22 & 65 \\
10 & 9.76 & 78 \\
11 & 6.79 & 53 \\
12 & 5.41 & 42 \\
13 & 5.64 & 44 \\
\hline
\end{tabular}

Since each box holds a different number of photographs, I decided to break the sample into sampling bins by box in order to get a proportionate sample of the collection. This would give me a sample most representative of the collection. Therefore, the results yielded from the sample should reflect the overall condition of the collection accurately.

Once I figured out the sample size for each box, I used a computer program developed by Matthew Ernisse, a computer programmer and my older brother, to generate random accession numbers for each of the thirteen boxes until I had a set of 785 random accession numbers. These random numbers from 1 to 2,960 are the sample that I entered into the condition report and represent the items pulled during my two-week visit to the Gepps Cross research centre.

\section{Layout of the Condition Report}

The condition report had to be easy to use and the data easy to analyse later. I chose to put the entire condition report into an Excel document so that later I could properly analyse the data and create charts from it. For conducting the condition survey of the sample, I created ten different categories of deterioration that I could score: tears/gouges/dents, abrasion, stains/foxing, grime/dirt/marks, silver mirroring, fading, mould/rodent damage, accretion, fingerprints and curling/cockling. In the category of tears/gouges/dents, I included any tears in the photograph or mount as well as holes, folds or gouges that caused a loss of image on the surface the photograph. For abrasion I counted any scratches or evidence where something had caused the surface to lose part of the image. Stains/foxing included not only foxing, but 
also any stain visible on the surface of the photograph or mount caused by spills or chemical deterioration. Grime/dirt/marks included the evidence of dirt on the photograph or mount, the evidence of marker, pen, ink or pencil and the residue of oils. The category of silver mirroring was limited only to silver mirroring and the category of fading is any kind of fading that caused a lightening of the photographic image. I defined mould/rodent damage as any kind of damage caused by water or mould, any rodent or insect. Accretion was limited to any substance that left a visibly raised residue, such as glue or sticky liquids. The fingerprints section was also limited to areas where the outline of a fingerprint was clearly visible on the surface of the photograph or mount. And lastly, the section for curling/cockling was applied to the overall flatness of the entire object.

Similarly, there were six categories for scoring the particulars sheets: tears/rips, embrittled/yellowing, marks/accretion, ink fading/bleeding, rodent/insect damage, foxing. These are more straightforward categories than the ones in the photographic portion. However tears/rips included excessive folds in the paper; marks/accretion also included stains from foreign substances, dirt, fingerprints and grime from oils. I cut out the section for mould damage since none of the particulars sheets showed any sign of water or mould damage.

When scoring these categories I used a scale of five different terms found in several condition reporting manuals. The scores are: negligible, slight, moderate, marked and extreme. ${ }^{2}$ Slight would show more deterioration than negligible, moderate more than slight and so on. ${ }^{3}$ For the data entry, I gave each score a number from 1 to 5 ( 1 being for negligible and 5 for extreme) so that I could turn the data into graphs that I could then analyse in later sections. For no signs of specific deterioration, the category was left blank, denoted by a zero.

\section{Conducting a Conservation Survey}

In considering how to approach a conservation survey, I consulted several professionals in the field who have conducted surveys before, including Grant B. Romer, Director of Conservation at George Eastman House. I also looked at many survey reports made by Luisa Casella, a fellow in the George Eastman House Advanced Residency Program in Photograph Conservation fellow. ${ }^{4}$ Using their advice and the survey reports, I was able to develop a list of questions to ask while conducting the conservation survey. Casella's guidelines helped me develop questions to ask at the site visit. ${ }^{5} \mathrm{I}$ also used a pre-visit questionnaire from Conservation Assessment Program while visiting the repository to develop my questionnaire. The C.A.P. is a program supported by the Institute of Museum and Library Services to help

\footnotetext{
${ }^{2} \mathrm{O}$ 'Reilly and Lord, "Basic Condition Reporting: A Handbook," (New York: Southeast Registrars Association, 1988), 4.

${ }^{3}$ Dudley and Wilkinson, "Museum Registration Methods," (Washington, DC: American Association of Museums, 1979), 240.

${ }^{4}$ Casella and Herrera, "Hispanic Society of America: Survey Report," (Rochester, NY: Advanced Residency Program in Photograph Conservation, 2007), 1.

${ }^{5}$ Casella, "Photograph Collections Survey: Guidelines Proposal," (Rochester, NY: Advanced Residency Program in Photograph Conservation, 2007), 1.
} 
guide institutions in collections management by conducting a general conservation survey of its collections. C.A.P. provided its form for the conservation survey online that I used in my research. I answered as many of the questions that I had developed as quickly as possible before the actual site visit date, which was 14 May 2008. The questionnaire I developed included, but was not limited to the following questions:

1. What is State Records's mission statement?

2. Do they have a collections policy and can it justify the WWI collection?

3. Who is the primary caretaker of the collection and responsible for preservation and access?

4. What is the history of the collection? (donor(s), year(s) of donation, subject, arrangement)

5. What is the history of the institution?

6. What is the original housing of the collection?

(a) Intimate enclosure?

(b) Secondary enclosure?

(c) Where in Sector D are they stored?

(d) What records are stored near them?

7. What is the current environment the collection is stored in?

(a) Size of the room?

(b) Environmental control system? (settings, 24/7 monitoring)

(c) Where are doors/windows?

(d) Are there disaster precautions?

(e) Is the air filtered?

(f) Are there any walls that lead to the outside?

(g) Where are the light fixtures?

(h) Where is the collection located within the room?

(i) Is there a pest management program?

(j) Are they in an industrial area/trucking route?

(k) Do they have a maintenance plan? Any issues?

8. What is the security of the building?

(a) Who monitors the Research Centre? 
(b) Who has access to the repository?

9. Who decides what objects go into Sector D?

10. Are there any finding aids at State Records?

11. Does State Records have an Emergency Disaster Plan?

(a) What disaster does it plan for?

(b) How often is it updated?

(c) Who is the disaster response team?

(d) Does everyone at State Records have a copy of the plan?

(e) What emergency systems are in Sector D? (ie. extinguishers, fire hose, fire supression system)

(f) Have they had any disasters in the past?

(g) What disasters are most likely in the area?

The biggest challenge about designing a conservation survey for State Records is that there has been "no real agreement within the profession as to the parameters of a comprehensive survey." ${ }^{\prime 6}$ With this in mind, I chose to consult professionals who have conducted conservation surveys and actual survey reports in order to understand possible "best practice" methods for conducting conservation surveys. I learned that a comprehensive and thorough questionnaire helped keep site visits on track, since there is so much information to gather in only a few hours. I also chose to take a digital camera along to record the repository doors, shelves and emergency systems where applicable.

I followed my questionnaire and the C.A.P. questionnaire closely during my visit. I kept in mind that I needed to have an overall idea of State Records' policies, practices, environment, security and emergency procedures by the end of the visit. What I could find out previous to the visit I recorded with the questionnaire, in case I needed any further information.

\footnotetext{
${ }^{6}$ Wolf, 1 .
} 


\section{Chapter 3}

\section{Institutional History}

\section{History and Structure of State Records}

State Records of South Australia functions as the state archive for permanent state government records as outlined under the State Records Act 1997. Over the years, State Records has gone through many structural changes since the State Archives Department was added in 1919 to the Public Library, Art Gallery and Museum of South Australia. In 1920, the archive opened the government and private holdings to researchers in its facility behind the Art Gallery on North Terrace, Adelaide. ${ }^{1}$ Even though the archive was begun as its own separate department, control of the Archives Department passed to the State Library in 1961. In 1969, the archive was moved into the basement of the State Library's building on North Terrace.

The next major change occurred in 1985 when the archive was divided into government holdings and private holdings. The private holdings were combined with the published material at State Library shortly thereafter to create the Mortlock Library of South Australia; these holdings are currently still under the control of State Library. At this time, the government archives became the Public Record Office, which was a division of the Department of Local Government. The Public Office left its space in the basement of State Records and in 1988 moved to the 'purpose-built' Gepps Cross facility, which was shared with the Australian Archives, and would later be known as the National Archives. ${ }^{2}$

In 1990, the Department of Local Government was dismantled leaving the Public Records Office under the control of the Department of State Services. At this time, the Public Records Office changed its name to State Records of South Australia. However, in 1997 State Records was incorporated into the Department for Administrative and Information services (DAIS). This was also the year that the State Records Act was created and put

\footnotetext{
${ }^{1}$ SRSA, "History of State Records," State Records of South Asturalia, http;//www.archives.sa.gov.au/about/role.html.

${ }^{2}$ Ibid.
} 
into effect. In 1999, State Records took over the entire Gepps Cross facility as the National Archives removed its records.

In 2006, further restructuring of State Records took place as the DAIS was dismantled during a restructuring of the public sector, leaving State Records to become a business unit of the Department of the Premier and Cabinet. Currently, State Records still operates out of the Gepps Cross facility with a four-sector repository and $75 \mathrm{~km}$ of records. It also has a City Research Centre on Leigh Street in central Adelaide. Additionally in 2003, State Records turned Sector D into its climate-controlled repository for the fragile documents that had been housed at the Netley warehouse since 1995. These fragile documents include the World War I portrait collection, which is now stored in Sector D at the Gepps Cross facility.

\section{Under the State Records Act 1997}

In the State Records Act 1997, the major functions of State Records of South Australia are clearly outlined. Some of the functions that pertain to the World War I portrait collection are listed below:

- To receive official records into its custody in accordance with this Act

- To ensure the organisation, retention, conservation and repair of official records in its custody

- To make determinations (with the approval of the Council) as to the disposal of official records under this Act

- To publish, or assist in the publication or indexes of, and other guides to the official records in the custody of State Records or official records whose delivery to State Records' custody has been postponed or is subject to an exemption granted by the Manager

- To provide for public and agency access to the official records in the custody of State Records in accordance with this Act ${ }^{3}$

These main functions of State Records outline its responsibility for the care and preservation of records in its custodianship. It also outlines its role in providing access of unrestricted records to the public; agencies can access even their own restricted materials. Under the Act, the functions of State Records include the creation of indexes, guides or finding aids to its records, which would include the WWI collection.

Also found under part two of the act, the objects of the Act clearly define the mission of State Records as the following:

\footnotetext{
${ }^{3}$ SRSA, State Records Act, (1997), 5-6.
} 
- To establish the Office of State Records as the principal repository for official records that are no longer required for current administrative purposes

. To ensure that official records of enduring evidential or informational value are preserved for future reference

. To promote the observance of best practices by agencies in their management of official records

- To ensure that each agency is afforded prompt and efficient access to official records in the custody of State Records for which the agency is responsible

- To ensure that members of the public have ready access to official records in the custody of State Records subject only to exceptions or restrictions ${ }^{4}$

Under this act, State Records becomes the custodian of these permanent records when they are transferred to its repository. However, the government agency that transferred that record still holds authoritative control over care and access of its records. Each agency is given its own unique agency ID that starts with GRG (government record group) or MRG (municipal record group) and is followed by a unique one, two, three or four digit number. So long as the records are unrestricted they are available to the public once transferred to State Records. The records include maps, plans, correspondence, files, volumes, audiotapes, videotapes, film, photographs and microfiche/film and can be used for various types of research from family history to government programs or policy, to immigration, shipping and historical events in South Australia.

\section{State Records and the World War I Portrait Collection}

The World War I Portrait Collection is protected under the State Records Act 1997 because it was created by the government department of the Public Library, Art Gallery and Museum of South Australia in 1918. It then passed to the Archives Department in 1919 and remained with the department throughout its changing history. When the Archives Department split in 1985 into government and private holdings, the collection remained with the government holdings. The photographic collection and surrounding records were under the Libraries Department and therefore a government record. By the time State Records of South Australia was officially established, the Libraries Department was given the agency ID of GRG26. The World War I portrait collection falls under this group and would naturally be under the authoritative control of the Libraries Department. However, since the department no longer exists, the complete care and control of the collection is now the responsibility of State Records.

\footnotetext{
${ }^{4}$ State Records Act, $4-5$.
} 
Since the World War I portrait collection is deemed a government record, it belongs under the custodianship of State Records under the 1997 Act. It can also be argued that the photographs must be retained at State Records because they have "evidential and informational value" that is important to family researchers and descendants of the soldiers, sailors and nurses represented. In some cases, they may be the only surviving photographic records of the South Australian volunteers who served in the First World War.

Also, since State Records is the sole custodian of the collection, it is completely responsible for care and access. State Records is accountable for the preservation, organisation, conservation and maintenance of the photographic collection under the Act. It is also required to create useful finding aids and indexes that facilitate the public and agencies in accessing the collection in the future. 


\section{Chapter 4}

\section{Collection History and Access}

\section{Photographs of Soldiers from the Great War, $1918-1952$}

In 1918, the Board of Governors of the Public Library, Museum and Art Gallery of South Australia put out a call to all South Australians asking them to donate their photographs of soldiers who had served in the Great War, now known as World War I. According to a record found in Libraries Department correspondence on 20th December 1918, several forms of publicity were used to reach potential donors:

1. small posters and notices exhibited throughout various offices and business places-including government departments-in the city

2. notices exhibited in the tramcars of the Municipal Tramways Trust

3. newspaper paragraphs

4. circulars to Ministers of City and Suburban churches

5. Lantern Slides screened in the principal Picture Shows in the city

6. personal application to soldiers and others by members of the staff ${ }^{1}$

The Public Library, Museum and Art Gallery also had seventy-four representatives in country towns hang posters and distribute circulars throughout their towns in order to spark donations. Copies of the circular and the poster can be seen in Appendices A and B. The letter also mentions that at the time, it had already collected more than sixty photographs from individual donors.

\footnotetext{
${ }^{1}$ GRG $26 / 5 / 7$, SRSA.
} 
Correspondence indicates that the department desired original photographs, not copies and requested that they be "cabinet size," which refers to the $6 \times 8$ in. size of State Records's cabinets in 1919 where the collection was stored. ${ }^{2}$ Each photograph turned in by a donor is accompanied by a particulars sheet that outlines the name of the soldier, date of birth, date of enlistment, trade, birthplace, address prior to enlistment, rank, number and battalion, as well as any other pertinent information.

According to the contemporary register, which lists when each photograph was received, the subject of the photograph, and an accession number, the collection was active from the years 1918 to $1952{ }^{3}$ The first photograph is registered on 22 October 1918. There is also one addition to the collection in 2002, suggesting that it is still open for donations. In original correspondence no deadline was suggested, but a quick donation was encouraged. By the end of 1919, the register shows that about 2,512 photographs had been donated; some days the department received as many as thirty a day. By 1920, the donations had tapered off drastically, with only 205 photographs collected in that year. In the years that followed, only a few each year were added to the collection. In 1931, seven photographs were donated and in 1940 there were only three. After 1940, there is a large gap in donations until one in 1952 and then donation altogether ceases until 2002.

In the circular, it is mentioned that the collection is part of a larger national collection. However, inquiries to other archives, libraries and museums in each Australian state found no evidence to suggest there was ever a national effort to collect all photographs of WWI soldiers, sailors and nurses. If this is the case, then State Records of South Australia holds a unique collection. There is also no information about whether or not the photographs were exhibited over the years or if they remained solely in the repository.

\section{Current Arrangement and Housing of the Collection}

The collection contains 2,960 black and white photographs both mounted and un-mounted, with a particulars sheet accompanying each photograph. The photographs are portraits of soldiers, sailors or nurses who served in the Australian Imperial Forces in World War I. Of the sample of the collection analysed in the condition report, approximately $54 \%$ of it was mounted (excluding cabinet cards). $34 \%$ of the photographs from the condition report were postcards and $9 \%$ were cabinet cards. The remaining $3 \%$ were un-mounted photographs of various sizes. ${ }^{4}$ From the sample, one can assume the collection mirrors these percentages closely and that the majority of photographs are mounted in some fashion.

According to the contemporary register, the collection is arranged in order of donation and numbered from 1 to 2,960 . This means that photograph 1 in the collection was the very first donation and entered first into the register. However, during the condition reporting, it was

\footnotetext{
${ }^{2}$ Letter to Mrs. M.B. Dailey on 4 February 1919 , GRG26/5/7, SRSA.

${ }^{3}$ GRG26/5/6, SRSA.

${ }^{4}$ Refer to the chart in Appendix F.
} 
discovered the arrangement was not that simple. In cases where there are multiple subjects in one photograph, a particulars sheet is filled out for each person and put into separate paper bags. The first bag contains the photograph and any subsequent bags contain only the particulars sheet and a paper referring the researcher to another accession number. In the register it shows that each person is given his or her own accession number based on order of donation, not merely by photograph. This also means that the collection holds fewer than the 2,960 photographs the numbering suggests; there are however, 2,960 soldiers, sailors or nurses represented in the WWI collection.

There are many factors to consider in this collection since the photographs were donated by thousands of individuals over the course of many years; the photographs collected also included many unique objects sent with them. Almost all of the photographs show the soldiers, sailors or nurses in their uniforms, but in a few cases men wore suits. Almost all of the photographs were taken in professional studios throughout Adelaide, though some are from Melbourne, Brisbane, Port Adelaide, Sydney, the United Kingdom and Cairo, Egypt. From each studio there is a wide array of backdrops, furniture, mounts and printing techniques that can be observed in the full-length portraits and headshots. To see examples from the collection, including particulars sheets, refer to Appendix C. Several photographs throughout the collection include more than the particulars sheet. In some cases memorial cards or additional letters outlining the soldiers' service or newspaper clippings are included. In the instance of photograph 1370, the donor included the soldier's letters to his mother, before he was killed in service. ${ }^{5}$

The photographs measure no larger than $6 \times 8$ inches in size. In cases where the photograph was larger, it was cut down to a $6 \times 8$ photograph, often by cutting off photographers' stamps and other embellishments on the mounts. The intimate enclosure for each photograph is a simple brown paper bag. Each paper bag is stamped with a seal that reads: P.L., M. $\mathscr{B}$ A.G. of S.A. Photographic Record. In the middle of the stamp is the unique number assigned to the photograph from 1 to 2,960. Figure 4.1 shows an example of a paper bag enclosure that has sustained some physical damage.

\footnotetext{
${ }^{5}$ Refer to Appendix D for photographs of the letter from 1370.
} 


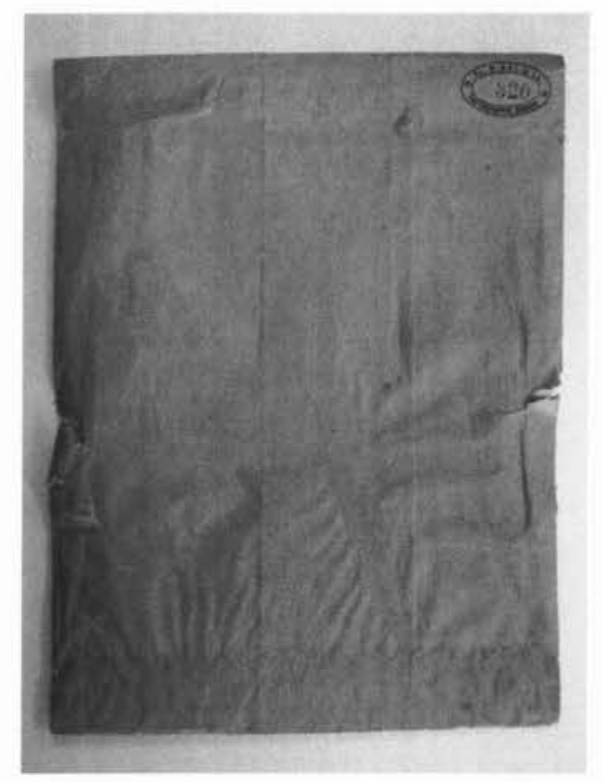

Figure 4.1: Intimate Enclosure

Many of these intimate enclosures have unfortunately sustained heavy damage over the years and in some cases offer little protection for the photographs. The enclosed photographs are then stored inside one of thirteen cardboard boxes, which function as a secondary enclosure shown below in figure 4.2 .

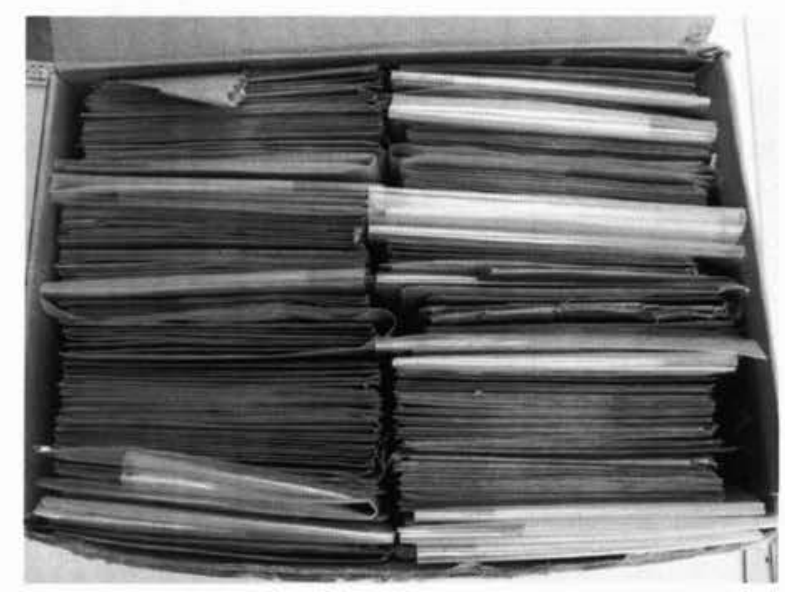

Figure 4.2: Box from the Collection

Groups of photographs are often tied together with linen string as seen in figure 4.3. The string holds the photographs together while they are stored vertically within the box, but as the illustration shows, the string often causes significant strain on the intimate enclosure as well as on the photographs. 
The thirteen boxes are stored in the climate controlled Sector D in the Gepps Cross repository. They occupy four and half shelf units in the middle of the repository; when stored, the collection is about 14.8 running feet.

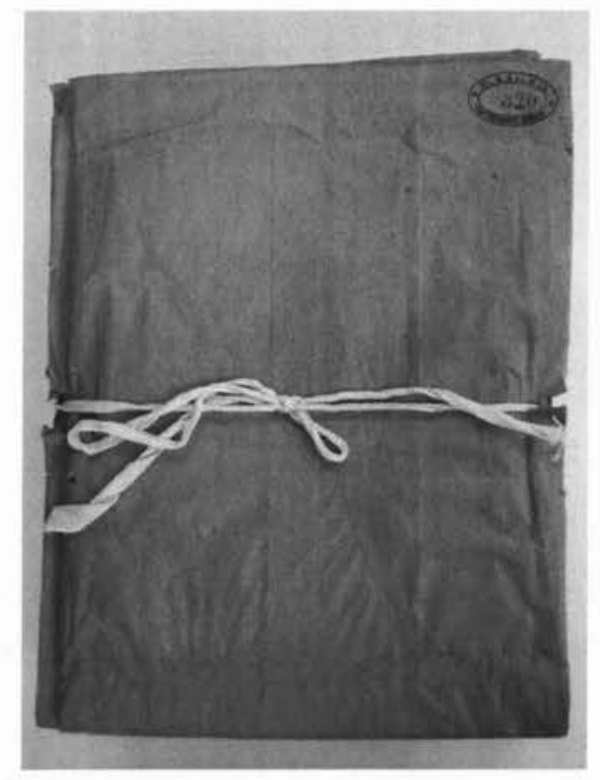

Figure 4.3: Use of Linen String

\section{Indexes, Finding Aids and Web Catalogue}

In accordance with the State Records Act 1997, State Records has created several finding aids for the WWI portrait collection. There is a contemporary index available in three card size boxes, one of which is illustrated in figure 4.4.

The boxes contain index cards with the name of the subject of the photograph and the number in the upper right corner inside the same stamp found on the intimate enclosures. These index cards were placed in alphabetical order by surname and for a long time were the only way to search the collection. More recently, a Special List has been added at the research centres, which gives an alphabetical listing of all the subjects in the WWI collection. But, instead of just giving name and accession number the Special List gives all the additional information found on the particulars sheets. The only information omitted is anything included under the 'additional notes' section on the back of the sheet.

A finding aid is also available as part of the web catalogue that allows the user to browse only the WWI Photos in Archives Search. The user is able to run a search for name, unit, number or corps in order to find whether or not the collection contains a photograph of that person. From that site, the photograph can be requested for retrieval and viewed at one of the two research centres. However, there are no digital images online and some information from the particulars sheet is not included. 


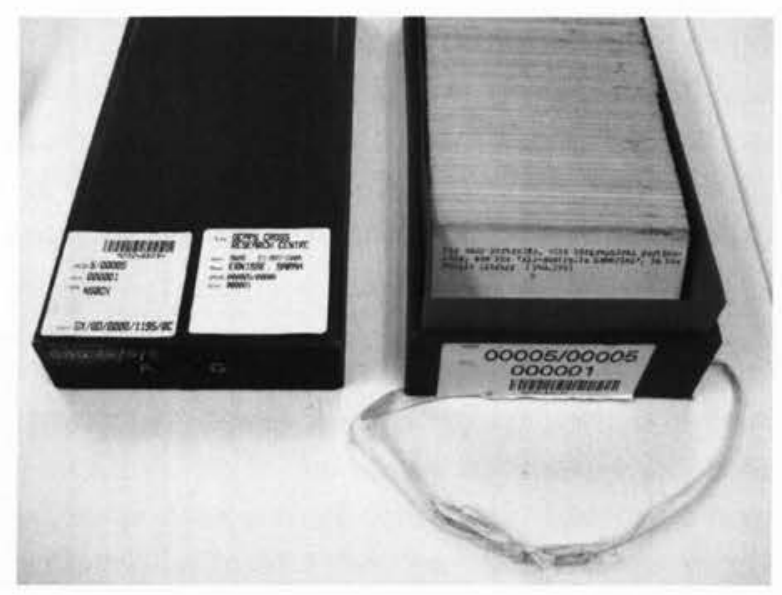

Figure 4.4: Contemporary Index

In the 1980s, the collection was put onto VHS tapes by taking stills of each individual photograph and putting them on VHS tapes for viewing at the research centres. The intent of the tapes was to enable people to view the stills to find the photograph they were looking for instead of handling all the individual photographs and sheets. This would have decreased the damage the collection suffered from handling. However, the tapes were difficult to read and slow to go through so they were seldom used as a finding aid; instead, they remain untouched in the repository.

The collection is also referenced in State Record's book Ancestors in Archives, which is a tool for researchers wishing to trace their family history. ${ }^{6}$ It is listed as one of the places that ancestorswho fought in World War I can be found. The book gives the accession number of the collection and suggests referencing the Special List for further information.

\section{Research and Access}

The collection is open to the public for retrieval and research. The entire repository at State Records has individual barcodes including the WWI portrait collection. The collection can be ordered for viewing one of two ways: by individual photographs or by entire boxes. In almost all cases, individual photographs are requested for retrieval. In some cases staff members order entire boxes, but it is rare that members of the public request to view the collection by box. Instead they order individual records to look through. When ordering records for the first time at one of the research centres, handouts of the rules and handling techniques are given to the individual to review before entering. They outline best practices to help ensure the preservation of this collection and all other collections at State Records.

\footnotetext{
${ }^{6}$ Hoyle, "Ancestors in Archives: A Guide for Family Historians to South Australia's Government Archives (South Australia: State Records of South Australia, 2000), 107.
} 
In Appendix E is a chart that shows retrieval requests from 2004 to 2008. The requests are broken down into three types of researchers: government agencies, staff members at State Records and members of the public. Public members have made the most requests for retrieval, with 155 out of 156 requests in 2006 and 160 out of 171 requests in 2007. This collection remains an important research tool for family historians, but also for scholarly researchers.

State Records developed a method to create a simple and streamlined method to retrieve items throughout the repository. When an individual item is requested, tags are printed to identify the item and its location, as is one made to identify the researcher. The photograph requested is then slipped in a plastic bag and both barcodes are placed on it. In figure 4.2 , there are several photographs inside the box that remain in plastic bags from previous retrieval requests. When a photograph is removed, a slip of blue paper with a matching barcode listing accession number and location is slipped into place, as seen in figure 4.5.

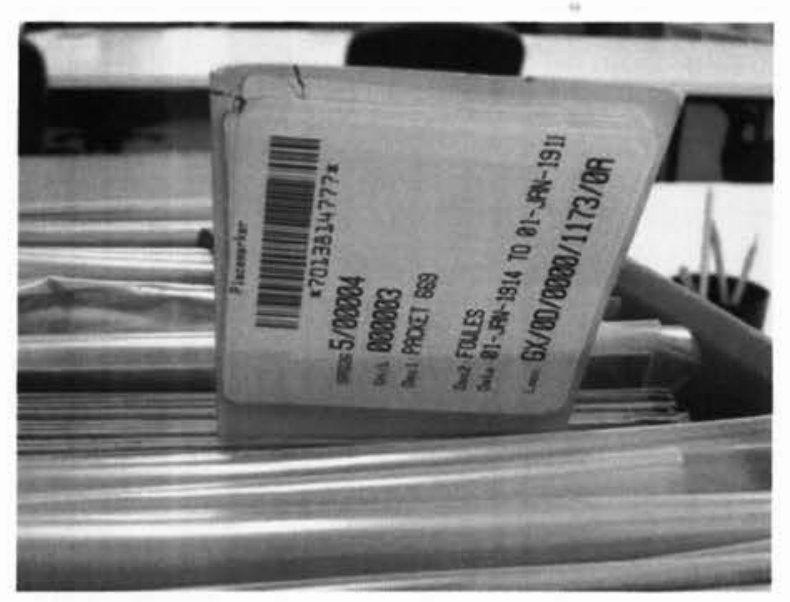

Figure 4.5: Retrieval Slip

This placeholder is removed once the photograph is returned and replaced.

Digital photography without flash is permitted of the WWI collection, whether or not the photographer is related to the subject of the photograph. State Records will photocopy the photograph for a small fee or outsource it to another professional printer for a substantially larger fee and better quality results. This choice depends on the quality the researcher desires. In special instances, State Records can digitise the photograph for a fee, though their scanning centre is small. In both cases, there are no restrictions on ordering a photograph; anyone can get a copy of any photograph unless special restrictions are placed on it. 


\section{Chapter 5}

\section{Condition of the Collection}

\section{Results from the Condition Report}

Charts made from the findings in the condition report show that there are three main types of deterioration found in the WWI portrait collection: abrasion (19\%), silver mirroring (17\%) and grime/dirt or marks (15\%). ${ }^{1}$ Fading, curling/cockling and stains/foxing were the fourth most common deterioration found ( $11 \%$ each). A very small portion of the sample did show some mould/rodent damage. Of the overall deterioration found in the sample, only $1 \%$ of it was mould or rodent damage. However, of this $1 \%$ no sign of mould damage was found. Only small, whitish nibble marks on the edge of the photographs showed any rodent or insect damage. These marks are commonly seen from silverfish, that chew at the gelatin surface, leaving behind nibble marks on photographs. All of the conditions appeared isolated from others in the box and therefore probably happened long before the collection traveled to the Gepps Cross repository.

Abrasion was the most common form of deterioration found in the photographs, as both minor instances with a few scratches and major instances with the loss of information. Some cases of silver mirroring were so severe that most of the image was clouded by the bluish sheen from the re-deposited metallic silver. Most of the cases are not that severe, but do obscure at least some of the image area. Fingerprint marks from handling the emulsion became more visible when photographs had suffered severe silver mirroring. Dirt and grime were most often found on the mounts of mounted photographs, which were often light, or where the most handling occurred. On heavily faded photographs, dirt was more apparent on the light surfaces.

Overall most of the collection is only slightly deteriorated, though signs of improper handling are visible on almost every photograph sampled. The photographs were often abraded to varying degrees, showed dirt or grime from hands and in some cases there were visible

\footnotetext{
${ }^{1}$ Refer to Appendices $\mathrm{G}$ and $\mathrm{H}$ for the charts of results from conditon report by box and for the overall sample.
} 
fingerprints. Less than $2 \%$ of the collection was severely deteriorated to the point where most of the image is lost or difficult to view properly. Some photographs from the same studio even showed signs of being in good condition, which can likely be attributed to high standards of processing at those studios or it is possible that these photographs were handled less.

The condition of the particulars sheets was also reported and the results show that the two most common types of deterioration were embrittlement of the paper and fading or bleeding of the ink (37\% each). ${ }^{2}$ These types of deterioration were expected, due to the nature of both the paper and the ink. The paper would have been created by a mechanical pulping process, which ground wood into short fibres that retained the lignin and other impurities of the wood. ${ }^{3}$ Over time, these impurities become acidic and will cause the paper to become yellow and brittle. The ink was most likely an iron gall ink, used until the early 20 th century. The ink was highly acidic; over time it would fade to brown and eventually burn through paper. ${ }^{4}$ In many cases, different stages of ink fading were visible, from slight to severe; in some places the ink had already burned through sections of the paper. Only the ink used in typewriters shows no signs of fading or bleeding. In almost all cases however, the ink was at least faded to a shade of brown. Where colour inks were used, the ink had faded severely and was difficult to read. Excessive handling of the sheets had torn them in a few instances and in many cases had left dirt, stains and some fingerprint marks on them.

The paper in contact with the photograph could have negative effects in the future with the possibility of acid migration. However, in some cases the particulars sheet protected areas of the photograph from oxidation. In other cases, ink transferred to the surface of the photograph or left marks on the mount.

\section{Influence of Current Housing}

The current housing appears original and in most cases ineffectual. Large rips and tears leave the edges of the photographs and particulars sheets exposed to further damage as seen in figure 5.1. The tear does little to protect the photograph and is almost the length of the entire envelope. As photographs were removed from the boxes, envelopes began to tear, despite best efforts to avoid the problem.

Since they are made of paper, the housing is opaque and therefore good at protecting the photographs against light, but makes viewing the photograph extremely difficult. These housings make it necessary to remove the photograph and particulars sheet with every use in order to view them. This has led to unnecessary abrasion of the surface of almost every photograph. Some cases are quite severe. Holes or tears in each envelope also do very little to protect against dirt and as they are handled by uncovered hands repeatedly, dirt and oils

\footnotetext{
${ }^{2}$ Refer to Appendix I for the chart of results from the condition report for the particulars sheets.

${ }^{3}$ Tuttle, 14.

${ }^{4}$ Ibid., 20.
} 
are transferred from the hand to the photographic surface. The envelopes have also aged considerably, becoming highly acidic; they have left the paper brittle and run the risk of transferring the acid to the particulars sheet or photograph.

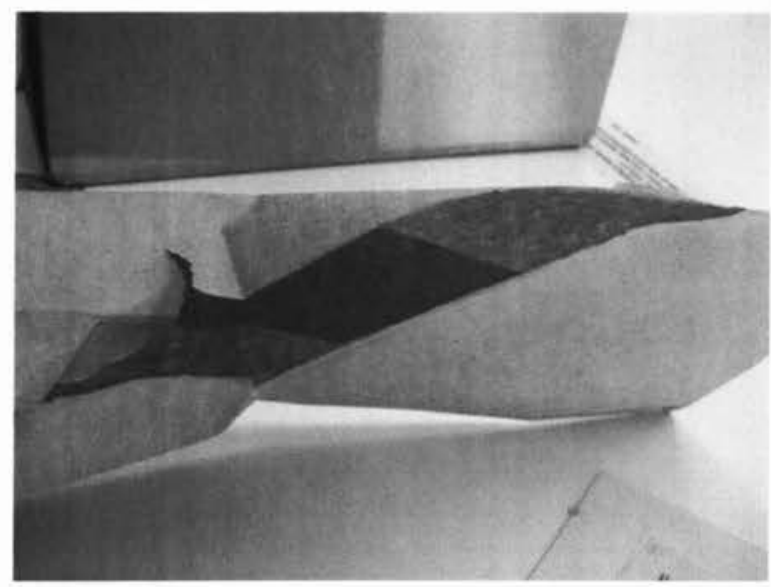

Figure 5.1: Damaged Intimate Enclosure

The current cardboard boxes in which the photographs are stored pose another problem. They are also old and slowly losing their firmness as they are handled repeatedly. The photographs are also stored too tightly within each box. In many cases, this not only damages the paper envelope further, but causes abrasion to the photographs and in several cases has caused curling of the photograph. Tying chunks of the collection together with string has also led to further physical damage of the photographs and housing both at the top and bottom of the stacks. In most instances, these housings do little to protect the collection. 


\section{Chapter 6}

\section{Repository and Environment Assessment}

\section{Repository Design}

Sector D is located in the upper right corner of the Gepps Cross building. While the building was constructed in the 1980s, the environmentally-controlled facility was constructed in 2003 and all the records currently in Sector D were moved from a controlled facility at Netley. The environmentally-controlled repository measures $23 \times 13$ metres. Sector D has a drop ceiling that is several metres below the building's actual ceiling. However, the repository does have two outside walls (which are outlined in red in figure 6.1). Fortunately, the WWI collection is stored in the middle of the repository and away from both exterior walls and so should not be affected by the varying exterior conditions. Figure 6.1 shows the location of the fire hose, extinguishers and the fire door on the far back exterior wall.

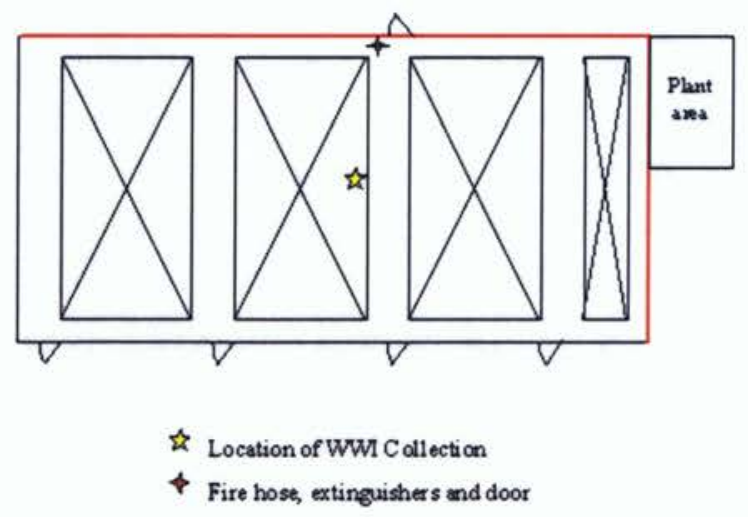

Figure 6.1: Sector D (not to scale)

There are four doors that access Sector D. They can be accessed through Sector C; those doors to Sector D are not locked, but the doors to Sector C are. The yellow star in figure 
6.1 shows where the collection is currently stored on metal shelves. Figure 6.2 shows the collection in storage. The metal shelves can be moved with a hand crank in order to access them.

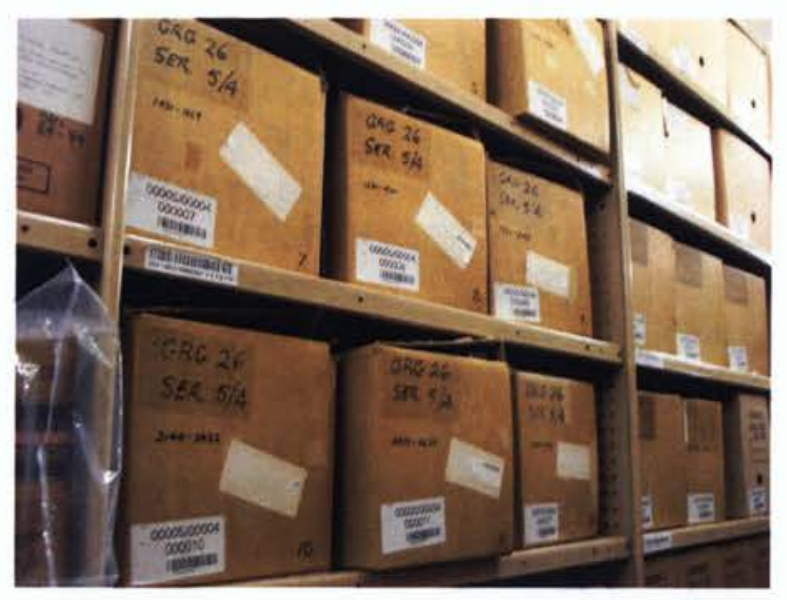

Figure 6.2: WWI Collection in Sector D

There is a lot of free space in Sector D. Currently, about 5826.55 metres are unoccupied and are not allocated to any records in the future. This means that there is space within Sector $\mathrm{D}$ to move the collection if re-housing it increases the running feet. At this time, there is no plan in place to find older or fragile records to move into Sector D, so the space should remain empty until the other repositories fill up with records and there is no choice but to place more records in Sector D.

Light levels within Sector D are not monitored, even though the lights are on motion sensors and thus on for a large portion of the day when the retrieval staff is moving around the repository. The lights are thin fluorescent bulbs and according the repository manager, there is no UV filter on them to protect the records from ultra-violet radiation. Florescent lights emit high levels of radiation, which causes irreversible fading to inks and embrittlement of photographic and paper materials. ${ }^{1}$ Since the collection is stored in both opaque intimate and secondary enclosures, less radiation penetrates the housing and saves the collection from excessive deterioration from light until removed for researching.

Pest and rodent management activity takes place frequently and though the maintenance is outsourced to another company, they are rigid about the maintenance plan. Even in the handling instructions handout to researchers, State Records asks that any mould, rodent or water damage be immediately reported to the nearest staff member. This way the problem can be quickly isolated, leaving the repository free from insects and rodents. As far as the WWI collection is concerned, it shows little to no rodent or insect damage, suggesting that the maintenance plan has kept the collection virtually free from infestation over the years.

\footnotetext{
${ }^{1}$ Tuttle, 38.
} 


\section{Temperature and Relatively Humidity}

The controls in the room are set for mixed media, which are about $20^{\circ} \mathrm{C}$ and $50 \%$ relative humidity (RH). For photographic materials, the recommendation is about $21^{\circ} \mathrm{C}$ and anywhere between 47 and $53 \% \mathrm{RH}$; according to these levels, the repository is acceptable for storing photographs. ${ }^{2}$ The HVAC system is outside the left outer wall in a locked plant area. The fences are about 10 feet high, corrugated steel and the door is padlocked at all times. Inside the area, the machines are mounted on a large concrete slab. There are two Carrier HFC-407C air conditioning units, two Carrier 39C Galaxy air handling units and one Munters ML1350 dehumidifier. All together, these units control the temperature and relative humidity for all of Sector D. They are specific to Sector D and do not control the environment in any other area. The machines have their own set of controls separate from the rest of the building and are left on all the time.

Temperature and relative humidity is monitored at two points throughout the repository all year long. Data from 2007 shows that the temperature and relative humidity in Sector D averaged from $20.88^{\circ} \mathrm{C}$ and $48.93 \% \mathrm{RH}$, remaining within acceptable levels for storing photographic materials. Appendix E displays the charts that show both the average daily temperature and average daily relative humidity fluctuations for each month in 2007. Daily fluctuations in temperature optimally should never surpass $+/-1.5^{\circ} \mathrm{C}$. $^{3}$ The chart for 2007 shows that only during the hottest months of the year (January and February) does the daily fluctuation rise above $+/-1.5^{\circ} \mathrm{C}$. During January, temperatures in the repository would rise above $25^{\circ} \mathrm{C}$, which is the maximum acceptable temperature for photographic storage $\left(20^{\circ} \mathrm{C}\right.$ $\left.-25^{\circ} \mathrm{C}\right){ }^{4}$ However, for most of the year, the temperature remains consistent and within the optimal range for storage.

The data chart for 2007 shows that the relative humidity in Sector D never reached above the maximum acceptable daily fluctuation of $+/-3 \% .^{5}$ In most cases the relative humidity stayed within the $47 \%$ to $55 \%$ optimal conditions for photographic storage. Only in some cases did it drop lower and it never fell below the $44 \%$ mark, even in the driest months. Between measurement points, however, there was usually a $1-2 \%$ difference in relative humidity, but they were almost always within the optimal conditions. The 2007 data shows that the conditions meet acceptable standards for daily fluctuations in temperature and relative humidity. On average, they stay within the optimal temperature and $\mathrm{RH}$ for storage, by averaging $21^{\circ} \mathrm{C}$ and $49 \% \mathrm{RH}$.

\footnotetext{
${ }^{2}$ Raymond H. Lafontaine, "Environmental Norms for Canadian Museums, Art Galleries and Archives," Technical Bulletin 5 (1979): 2.

${ }^{3}$ Ibid.

${ }^{4}$ Ibid.

${ }^{5}$ Ibid.
} 


\section{Air Quality}

The air handling unit includes a filtration system comprised of several different kinds of filters, but the repository manager did not know what filters State Records uses in the Carrier 39C Galaxy units. Since State Records is on a maintenance plan in which it has outsourced all the work on the HVAC systems, the staff knows very little about the machines. Since the new annual plan had not been turned in from the maintenance company, there was no information on how often the filters are changed, though according to the repository manager, Michael Fidler, it is usually every couple of months. The manufacturer, Carrier, has several different kinds of filters available for the air handling units, but when contacted, the representative explained that filters are chosen based on the needs of the consumer and had no information about State Records. However, the representative suggested using high efficiency G4 filters, the DOP range and activated carbon filters in a heavy industrial and trucking area. G filters are course filters and G4 is the highest efficiency G filter available from Carrier, which is $90 \%$ to $95 \%$ efficient at trapping particles. ${ }^{6}$ The G4 filters trap larger particles from about five microns to ten milimeters in diameter that inlude heavy industrial dust, ashes and pollen. The DOP range are $95 \%$ to $99.999 \%$ efficient fine filters. The filters available in this range are H10 - H14 and E10 - E14 from Carrier. These fine filters trap particles from ten nanometers to ten microns and include suspended dush, soot, smog, haze, oil-fire smoke and ashes. The finest filters available are the activated carbon filters that trap particles as small as five nanometers, such as gas molecules and metallic dust. The filters designed and suggested by Carrier are in accordance to European Union Standards, EN 779 and EN 1822. ${ }^{7}$

A combination of those three filters should be used in the air handling units in Sector D. It is important that State Records knows how what type of filters it uses because the facility is located both on a trucking route and in an industrial area. Both of these release high amounts of gaseous pollutants in the air as well as soot and other particulates. Gaseous pollutants from cars and industry "bond with oxygen to produce corrosive chemical compounds which leave paper and photographs weak, brittle and stained." 8 Because of State Records's location in Gepps Cross, it is important that it has a robust air filtration system-or that staff is aware of the strength and drawbacks of the current system - to prevent these pollutants from causing corrosive damage to the WWI collection and other records stored in the repository.

\section{Film-Based Materials and other Issues}

Over the past fives years, the roof has been leaking in the repositories, which is important when considering the preservation of the collection. No damage was done to any records while

\footnotetext{
${ }^{6}$ Carrier, "Air Handling Units Product Information," http://eto.carrier.com/litterature/psd/13903.pdf (assessed May 18, 2008), 9.

${ }^{7}$ Ibid.

${ }^{8}$ Tuttle, 40 .
} 
the roof leaked, but there is potential if the roof is not properly maintained in the future. Roof maintenance must be monitored and leaks immediately patched. Since Adelaide has a very dry climate, it is easy to let a roof fall into disrepair, until a downpour comes and the leak causes serious damage to records. Fortunately, Sector D has a second roof to offer extra protection in case the building roof does leak. This has been the first year that the roof has not leaked in the repository, which was tested during the conservation survey as Adelaide had several days of torrential rain. There were no leaks found in the repositories during that storm.

However, there is another issue present within Sector D that could have an effect on both the WWI collection and any other record in the repository. The right side shelving units are home to several canisters of film from many early collections. Figure 6.3 and figure 6.4 show the shelving units where the film is stored and an example of the varying types of containers the films are stored in.

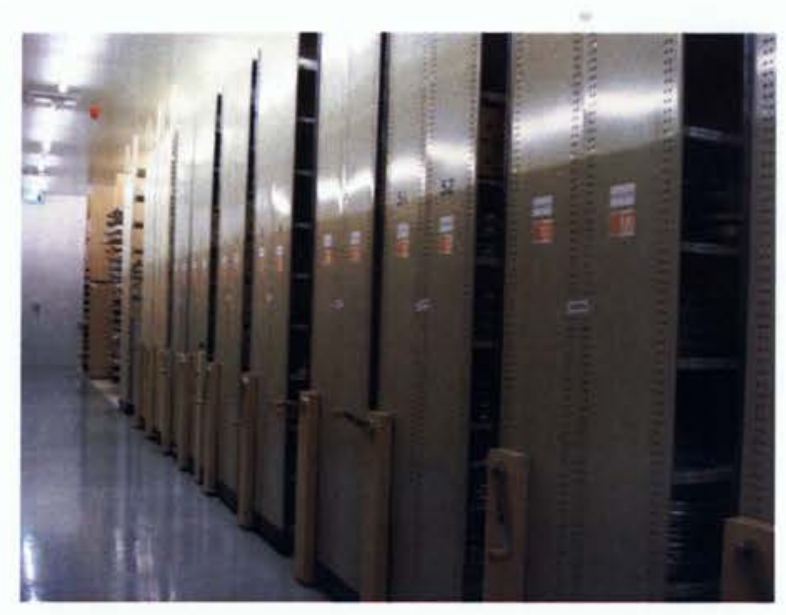

Figure 6.3: Film Storage in Sector D

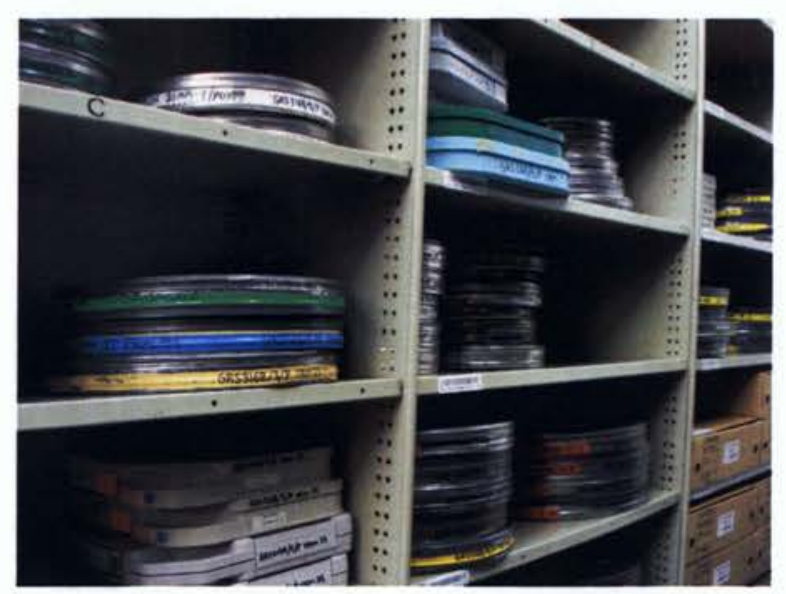

Figure 6.4: Example of Film Containers 
The films range from about 1916 to the 1980s and are still stored in their original canisters, both metal and plastic. Some of the early films are from GRG7, the Publicity and Tourist Bureau; there are about 186 items that range from 1916 to 1970. Most of the films have VHS copies, but staff members are not sure if they are all completed and if the tapes are high quality reproductions. The films are not identified as acetate or nitrate based, however from many of the canisters a very distinct vinegar smell was present; at least some of the collection is therefore acetate and already in the beginning stage of deterioration from vinegar syndrome.

The film collections probably contain both acetate and nitrate films. Little is known about their current condition and whether there are films with severe deterioration that need immediate action. It is important that these films be quickly identified and removed from the repository because they can be harmful to other records in Sector D. Nitrate film damages material it is in close contact with. At a certain point of deterioration it becomes extremely volatile, especially when in containers where there is no air circulation to release the nitrogen oxide it off-gases, which "forms nitric acid in the presence of moisture." Many institutions isolate their nitrate film in either cold storage facilities or off site in order to protect against the threat of fire. Nitrate and acetate film should be separated from one another as well as from the other records. These films should be assessed before they have deteriorated beyond use and begin to have an adverse affect on other records around them.

\footnotetext{
${ }^{9}$ Valverde, Photographic Negatives: Nature and Evolution of Processes (Rochester, NY: Advanced Residency Program in Photograph Conservation, 2005), 21.
} 


\section{Chapter 7}

\section{Emergency Planning and Security}

\section{Emergency Disaster Plans and Preparedness}

Inside Sector D as well as throughout the rest of the repository there are several fire suppression systems in place. The overhead fire suppression system is a water sprinkler, which was chosen at the time because it was most cost effective, according to the repository manager, Fidler. This is not an ideal situation since a pipe could burst and leak water into the repository, damaging records; if there was a fire and the sprinkler system went off, many records would also sustain water damage, unless they are protected by waterproof housings. However, the cost of changing the sprinkler system to gas would be a costly burden for State Records. In the back of the room next to the fire exit is one fire hose, another fire suppression system, shown in figure 7.1.

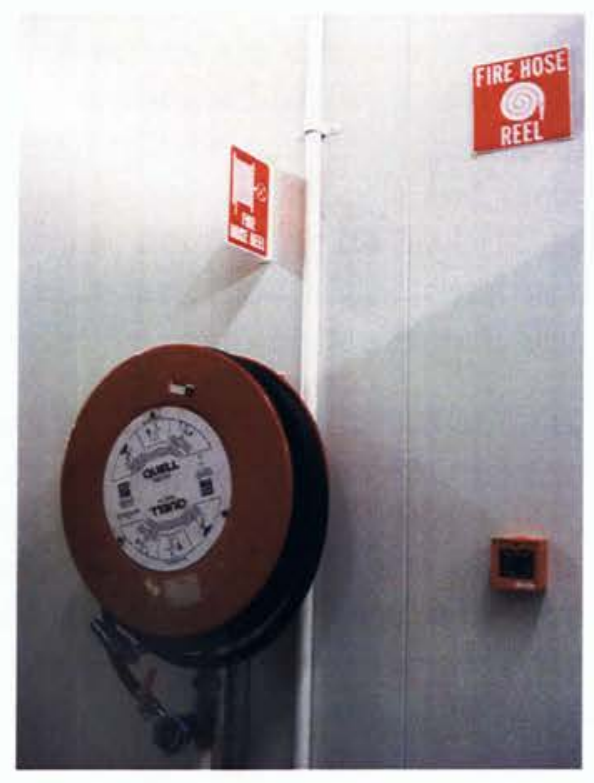

Figure 7.1: Fire Hose 
Next to the fire hose are one carbon dioxide and one water extinguisher shown in figure 7.2. All systems are under a maintenance plan with the installation company and are checked regularly, though from year to year the maintenance plans change.

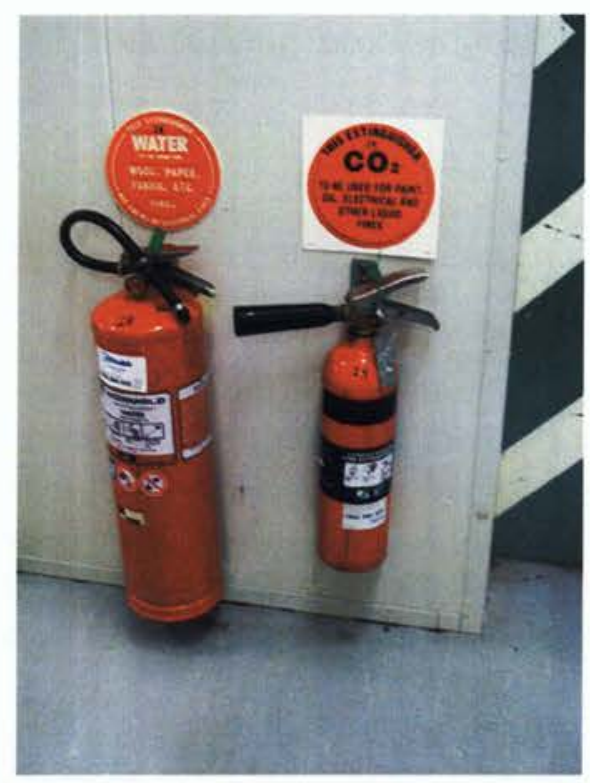

Figure 7.2: Fire Extinguishers

State Records also has an extremely detailed and large Emergency Disaster Plan booklet, which for privacy reasons and size, is not included in the Appendix. The plan was created in 2007 by outsourcing the task to Artlab, the South Australian government conservation laboratory. The plan has been organised to be updated yearly, with an update added for 2008. State Records chose to outsource the creation of a disaster plan because it does not have the experience, training, space or staff to handle a disaster. In all emergency situations in the disaster plan, Artlab staff will be onsite to provide assistance with record salvage. The plan also outlines high priority salvage records and their location. Among the first to be salvaged is the WWI collection, illustrating its importance to the institution, as well as recognising its fragility and age. In fact, most of the items on the list are located in Sector D where the oldest, rarest and most fragile items are stored, including the WWI photographs.

Along with disaster procedures other important information is included. A list of companies is available for different kinds of disaster recovery in a variety of areas from clean up to electronic media, audio-visual, film reprocessing, freeze drying, storage and cataloguing. In the event of a disaster, many of these problems will need to be outsourced and having a previously made list of these companies shows good disaster planning, so long as the list is updated often. There is also the list of disaster team roles and annually updated information for them. The roles are: leader, liaison officer, supply officer, record keeper, finance delegate, collection subject specialists, building facilitator/maintenance office, environment monitor, salvage workers and first aid officer. Everyone on the team has a copy of the disaster plan and contact information of each team member in the event a disaster takes place. 
Aside from disaster plans, there are also preparation and inspection procedures for poor weather conditions in order to protect against them becoming disasters. There are procedures in case of: bushfire, earthquake, flood, power failure (brown outs), security alert or wet and windy weather. These procedures are ideal because they help ensure that a small problem is rectified quickly, preventing it from turning into a major disaster that could damage large portions of records in the repository.

\section{Security at State Records}

State Records relies on swipe card access to the repository areas. Once in Sector C, however, the doors to Sector D are not accessed by swipe card, though a swipe card is required to enter any of the three doors to Sector C. Every staff member at State Records has a swipe card that will give him or her access to the repository, but only about half are actually involved in the retrieval of records. Most of the staff members do not enter the repository or know how to use the computer system to locate or retrieve items even though they have access to the repository.

The research centre must also be entered and exited with either a swipe card or by being buzzed in and out by the attendant at the information desk. In order to be buzzed into the research centre, one must present his or her membership card to the information desk; if he or she does not have one, a membership card can be obtained on the spot. Once inside the reading room, a researcher must wait to be buzzed out. This allows the staff to check to make sure no one leaves the research centre with records. Security in the research centre extends to a list of rules given with to each person who signs up for a membership card. The rules outline the restriction of bags, food, drink and pens. These restrictions not only ensure the security of records by preventing stealing, but also protect against damage to the records.

Other security procedures to protect against damage of the records and ensure their future preservation include a handout on the proper handling of archival records. The handout includes instructions to ask for the assistance of research centre staff instead of forcing open books, volumes or files. Likewise, the research centre rules instruct visitors to follow any instructions or requests from the staff members and to refer to the handout on handling for the proper method of looking at records. ${ }^{1}$ Both documents warn against marking an original document in any manner, which under the State Records Act 1997 is a crime that can include a maximum penalty of $\$ 10,000$ (AUD) or two years imprisonment. Aalso stressed in the opening of each leaflet is the importance of taking care when handling these records to "ensure their availability to the future."

\footnotetext{
${ }^{1}$ From the handout "Research Centre Rules" available at State Records of South Australia.

${ }^{2}$ From the handout "Handling Archival Records" available at State Records of South Australia.
} 


\section{Chapter 8}

\section{Collections Care Proposal}

This proposal contains three types of recommendations for State Records of South Australia regarding the WWI portrait collection, collected from 1918 to 1952 . The data supplied from the sampled condition survey of the collection and the conservation survey served as the evidence for these recommendations. These recommendations are meant as a guide to help improve the preservation of a culturally and historically relevant collection over the next ten years. The immediate recommendations are crucial to the current state of the collection, with short term following closely behind. However, some of the short-term recommendations will require longer planning periods in order to allocate appropriate resources once a method of approach is chosen. For the housing recommendations, four examples are included as a guide for State Records when deciding what type of housing best meets the collection's needs as well as State Record's abilities and resources.

These recommendations are best practice but due to time, money, space and staff requirements alterations may be needed. However, these recommendations need careful consideration in order to protect the collection in the future. Looking after the preservation of the collection is far less costly than conservation treatments or losing parts of the collection completely. They are unique and for that reason alone, better preservation standards are needed so the photographs survive for future generations.

\section{Immediate Needs (less than 1 year)}

1. The War Memorial in Canberra should be notified about the existence and details of the collection.

Upon a brief dialogue with the War Memorial during the preliminary stages of the project, it came to my attention that the War Memorial did not know of the existence of the WWI portrait collection held at State Records of South Australia. The staff was curious to learn more, though at the time I had very little information to give. This collection would be of interest to the War Memorial since it deals with the involvement 
of Australia and its citizens in war. However, the War Memorial currently has no information about the scope of the collection, finding aids, history of the collection and how to access the collection at State Records.

If State Records is worried that the collection would suffer further handling damage before the re-housing project, then it can wait to notify the War Memorial about the WWI collection. However, increasing the user requests for the collection may help make a stronger case for re-housing the collection as soon as possible. In my opinion, the collection would benefit from increased use, since it would draw attention to its inadequate housings and need for digitisation. Utlimately, State Records must decide what it thinks is best for the collection. If this knowledge were passed on to the War Memorial in the form of an e-mail or letter, the staff could help direct researchers to the WWI collection, who might not otherwise know about it.

\section{Make an assessment of the current air filtration systems in Sector D.}

As it stands, there is little information at State Records about the current air filtration systems and the standards that they meet. If the system is actually inadequate at cleansing the air properly, harmful gaseous pollutants and particulates are making their way into the repository and acting as catalysts in deterioration. This can create a serious problem, even if the temperature and relative humidity are kept at acceptable levels; the pollutants will still speed up oxidation and cause harmful abrasion and fading. And since State Records is located on a heavy trucking route and in an industrial area, it is important that the filtration system is up to standards for protecting photographic collections - as well as other media.

In order to protect the collection further, an assessment should be made to check for the following things: frequency of purification, presence of charcoal or carbon filters and range of filtration. ${ }^{1}$ The frequency of purification of the air in the repository should be at least three times an hour. Charcoal or carbon filters are recommended because they effectively remove fine, gaseous pollutants, which are harmful to records. Carrier recommends the use of high efficiency G4, DOP and activated carbon filters to remove course and fine particulates found in heavy industrial areas. However, there was no documentation on the types of filters used in the Carrier air handling units in Sector D. The current air filters used in Sector D's air handling units should be assessed so see if they contain these filters or high efficient equivilents and if they do not, then consideration should be made on how to improve the system; if the system is close to meeting proper filtration requirements, it is satisfactory and needs no alteration. However, air filtration should be monitored in the long term in case conditions worsen.

\section{Identify and assess all film currently stored in Sector D.}

Since it has been established how volatile and extremely flammable cellulose nitrate film can become, it is important that the motion picture film held at State Records is immediately identified and assessed. The first step that must be taken is to identify both the cellulose nitrate and acetate films in Sector D. At the very least these films

\footnotetext{
${ }^{1}$ Tuttle, 41.
} 
must be isolated from other records as well as from each other. Deteriorating nitrate film can harm other records in close contact. Deterioration of nitrate and acetate films cannot be stopped; it can only be slowed down through proper storage. If steps are not taken to improve the current condition of these motion picture films, they will deteriorate to a point where they can no longer be viewed and all information is permanently lost.

Once the nitrate and acetate film are identified, they need to be assessed as to how deteriorated they are. If they are severely deteriorated, they might not be salvageable. Those that are slightly deteriorated can still be digitised. Once they have been identified and assessed, the nitrate film should be digitised if it is not already and then the film destroyed according to handling hazardous material regulations. Since they are identified as hazardous material, they must be handled and disposed of properly according to law. However, during the digitising process, the film should be stored separately from all other records. The acetate film can also be digitised and destroyed if desired, or else steps to create frozen cold storage should be made. There are several options for cold storage available and if the collection is going to survive, then it requires cold storage. The films also need to be isolated from other records in order to protect the other records from harmful off-gases.

Before beginning to identify and assess the state of the film, Artlab should be consulted. They also should have proper information on how to correctly dispose of nitrate film. While nitrate film can be kept in the future as long as stored in frozen conditions, it might be too costly for the institution and therefore digitising might be the more cost effective answer. It is up to State Records to decide if it would rather have cold storage or digitise the film, but something must be done to the film collection in Sector $\mathrm{D}$ in order to protect both the information on the films and the other records in the repository.

\section{Short Term Goals (maximum 3-5 years)}

\section{The arrangement should be assessed and plans implemented for the re- arrangement of the collection.}

The current original arrangement reflects the number of people represented in the collection, but does not adequately reflect the number of individual photographs in the collection. While the idea of arranging the photographs from first collected to most recently collected leaves the collection open to future donations if State Records decides the addition of another photograph would enhance the collection, the gaps created by giving individual people accession numbers without photographs becomes confusing, when retrieving records. For example, the first record may guide the researcher to another record, causing him or her to wait twenty minutes to an hour before the record is retrieved, just to view the photograph. The collection will remain searchable by name, but with a new arrangement, one record may have three names attached to it if there are three subjects in the photograph. Combining the records of multiple 
subjects from the same photograph would decrease the amount of items retrieved and waiting period for the researcher.

Before re-housing, State Records should consider re-arrangement of the collection; the arrangement would include all the subjects of one photograph as one record. This should make searching and retrieving records significantly easier, though changes will need to be made to the current finding aids and the web catalogue. Rearranging the collection by condensing the subjects of group photographs into one record will also make housing the collection later easier as it eliminates the need for additional housings. If State Records does decide to change the collection arrangement in any way, notation must be made on the web catalogue and in finding aids about the original accession number of each record. This will help maintain the original integrity of the collection and allow researchers to find records they had searched for before the re-arrangement.

\section{The photographs in the WWI collection should be re-housed in order to protect them against deterioration.}

This is an important step for the collection since the original housing is ineffective. The collection needs proper housing to protect the records from handling damage as well as damage from pollutants, dirt, light, oil, water and other harmful agents to deterioration. All the materials chosen for the following four housing options are either from Conservation Resources in Victoria or Albox in Adelaide, SA. All materials have passed the Photographic Activity Test, which means they are proven to be chemically neutral and do not harm photographic materials over time unlike the current housing; the current housing is releasing acids, which in many cases have begun to affect the photographs as well as the particulars sheets.

It is important to take into account when reviewing the options that the total prices merely reflect materials and approximate labour costs; they do not reflect possible miscellaneous costs required to complete the project. However, these costs are far less expensive than the cost of conservation treatments in the future to repair the damage these photographs will likely sustain if left in the current housing.

The labour costs were estimated based on the average salaries for an archivist working in Adelaide; I received the salaries from professionals from different Adelaide archives, libraries and museums. The average salary is approximately $\$ 44,000$ (AUD) per year, or $\$ 3,666.67$ per month. I assumed that one salaried archivist would be given the re-housing project. The longest re-housing project is option 2 (page 39) and assuming a typical work week is 37.5 hours, it would take about two months to complete. The other options have pre-made materials and would approximately take half the time to re-house, or approximately one month. These are only estimates of labour costs and may vary depending upon expertise, salary and unforeseen circumstances during the project.

When the collection is re-housed, the number of units the collection is stored in will most likely increase and this will need to be noted in the catalogue. The location of the collection might also need to change as the collection might require more space within the repository. Since Sector D still has a lot of unused space in it, increasing the size 
of the collection should not be a huge concern; however, space is limited in the overall repository. It should be kept in mind when designing a new housing for the collection.

\section{Four Housing Proposals}

Four examples of housings have been designed to give an idea of how to re-house the WWI collection. This gives State Records flexibility to choose the housing it thinks will work best with researchers and with the way the staff access and retrieve the collection. It also gives an idea of the kinds of materials out there and how best to house a multi-media collection, keeping in mind how important protection is to the preservation of the photographs. When choosing one of these four options or making adjustments to them, it is important to remember that at the very least every photograph must have individual enclosures; this protects the photographs from damage from handling, dirt and pollutants. ${ }^{2}$ Also, un-mounted prints should have an intimate enclosure that provides a rigid support to avoid curling or tearing in the future. Each of these four options has both an intimate enclosure and a secondary enclosure. In the case of options 2 and 3, there is an intimate enclosure for the photograph and then one for the rest of the components in the record. Since the collection involves records with multiple multi-media objects, finding suitable enclosures is difficult; the fact that some records contain more objects than others also adds to the complication of finding suitable, affordable housings.

\section{Option 1}

The components of option 1 come exclusively from Albox in Adelaide. This option places the photographs into plastic sleeves inside archival plastic three-ring albums. The pages can easily be removed for retrieval and replaced later. The plastic album sheets are also archival and contain two $6 \times 8$ inch slots. In one side the photograph can be placed, while on the other side the particulars sheet and other papers from the record can be placed.

\section{Advantages:}

- The materials come from a local vendor that makes shipping cheaper and faster; this local vendor supplies to other local archives and may be willing to offer a discount.

- The acidic papers are separated from the photograph, which protects the photograph and makes the photograph easier to view.

- The plastic enclosures are transparent so the photograph does not need to be removed by researchers for viewing. This cuts down on handling damage caused to the individual photographs.

\footnotetext{
${ }^{2}$ Reilly et al., 8 .
} 
- Plastic also protects better against environmental pollutants, which deteriorate the image quickly.

\section{Disadvantages:}

- Plastic has a low melting point and can irreversibly bond with the photograph in a fire.

- Un-mounted photographs have no rigid back support included in this option, though one can be added, which will drive up costs. Should rigid boards be added, they must be lignin-free, archival white or off-white boards only; coloured boards can deteriorate or bleed colour onto the photograph.

- Should the relative humidity become uncontrollable, this could cause moisture to trap inside the plastic enclosures and create what is known as ferrotyping. This is when the image will stick to the enclosure, permanently damaging the surface of the photograph. ${ }^{3}$

\section{Materials:}

\section{6x8 Archival Plastic Photo Album Pages, 100 pack}

Order \#: 8x6-100

Size: $315 \mathrm{~mm} \times 255 \mathrm{~mm}$

Price: $\$ 48.21$ (AUD) per pack

(1 photograph per page means 100 photographs per pack)

Need about 30 packs@ @ \$48.21 (AUD) a pack $=\$ 1,446.30$ (AUD)

40mm Binder and Cover, Charcoal Grey (Also comes in Oxford Blue, Grey or Black)

Order \#: 40BSCCHGY

Price: $\$ 19.49$ (AUD) each

(Will hold about 50 photos each album)

Need about 60 albums @ $\$ 19.49$ (AUD) each $=\$ 1,169.40$ (AUD)

Total cost of materials $=\$ 2,615.70$ (AUD)

Total cost of labour (one month) $=\$ 3,666.67$ (AUD)

\section{Option 2}

This option is by far the cheapest option in terms of materials, but needs the most labour. It uses archival cardboard boxes and archival file folders to hold all the materials and special plastic intimate enclosures to protect the photographs. The file folders purchased must be

\footnotetext{
${ }^{3}$ Ogden, "Preservation of Library and Archival Materials: A Manual" (Andover: Northeast Document Conservation Center, 1994), 164.
} 
cut in half to fit into the cardboard box and therefore cut down on materials cost. Boxes should not be filled too full and if the last one is partially empty, a spacer should be made from archival materials to keep the records vertical while in storage. Rolls of Melanix (75 micron) are used to create plastic sleeves with a one inch flap that goes over the photograph. Un-mounted photographs have a rigid backing of $6 \times 8$ inches that is also enclosed in the plastic sleeve to offer added protection. All of the materials for this option are purchased from Conservation Resources in Victoria.

\section{Advantages:}

- The sleeves can be pulled open easily, instead of having to pull the photograph out of a sleeve. This reduces abrasion if the photograph must be removed from the plastic enclosure.

- The plastic enclosures protect the photographs against environmental pollutants.

- The plastic enclosures have rigid backing for un-mounted photographs, offering added protection from curling and tearing.

- The plastic enclosure is transparent so the photograph can be viewed without removing the photograph from its enclosure; this greatly reduces handling damage.

\section{Disadvantages:}

- The rigid backing is opaque so photographs must be removed in order to view the back.

- Plastic has a low melting point and can irreversibly bond with the photograph in a fire.

- If the relative humidity cannot be controlled, then the photograph could ferrotype to the plastic, destroying the photographic emulsion.

\section{Materials:}

\section{Prolong 500 year Archival Corrugated Boxes, 50 Pack}

Order \#: Box 1-50

Size: $168 \times 371 \times 250 \mathrm{~mm}$

Price: $\$ 158.00$ (AUD) per pack

1 pack of 50 boxes $=\$ 158.00$ (AUD)

\section{Prolong Melanix Polyester Film}

Order \#: PPF-75UM-100

Size: (75micron) $1016 \mathrm{~mm} \times 100 \mathrm{~m}$

Price: $\$ 278.18$ (AUD) per roll

(can make about 1,514 $6 \times 8$ inch sleeves with 1 inch flaps per roll)

2 rolls @ $\$ 278.18$ a roll $=\$ 681.75$ (AUD) 


\section{Prolong Archival Mounting Card (Natural), 15 Pack}

Order \#: PAMC-FC-N-25

Size: Foolscap 216 × $330 \mathrm{~mm}$

Price: $\$ 12.73$ (AUD) per pack

(1 sheet makes $26 \times 8$ inch rigid supports)

22 packs @ $\$ 12.73$ each $=\$ 280.06$ (AUD)

File Folders, 100 Pack

Order \#: PFF-100 Folder

Size: Foolscap 240 x $355 \mathrm{~mm}$

Price: $\$ 45.45$ (AUD) per pack

( 1 folder cut in half makes two folders, so there are 200 folders per pack)

15 packs @ $\$ 45.45$ each $=\$ 681.75$ (AUD)

Total cost of materials $=\$ 1,676.17$ (AUD)

Total cost of labour (two months) $=\$ 7,333.34$ (AUD)

\section{Option 3}

This option is the second most expensive, but removes the need for so much labour when creating plastic envelopes that option 2 requires. This is identical to option 2, but instead of making the plastic sleeves from rolls of Melanix, the sleeves come assembled. These sleeves do not have the flap in option 2, which allows the photograph to be removed by pulling open the sleeve instead of pulling the photograph out of the flap. As in option 2, the file folders purchased must be cut in half to fit into the cardboard box and therefore cut down on materials cost. Boxes should not be filled too full and if the last one is partially empty, a spacer should be made from archival materials to keep the records vertical while in storage. All of the materials for this option are supplied by Conservation Resources.

\section{Advantages:}

- The plastic enclosures protect the photographs against environmental pollutants.

- The plastic enclosures have rigid backing for un-mounted photographs, offering added protection from curling and tearing.

- The plastic enclosure is transparent so the photograph can be viewed without removing the photograph from its enclosure; this greatly reduces handling damage.

\section{Disadvantages:}

- Removing the photograph from the plastic sleeve would most likely cause more abrasion and other handling damage then the sleeves in option 2 . 
- The opaque rigid back support would require photographs to be removed from the enclosure in order to view the back side.

- Plastic has a low melting point and can irreversibly bond with the photograph in a fire.

- If relative humidity cannot be controlled, then the photograph could ferrotype to the plastic, destroying the photographic emulsion.

\section{Materials:}

Polyweld Polyester Sleeve (Style A), 100 Pack

Order \#: PWA-A-6x9-100

Size: $6 \times 9$ inches

Price: $\$ 78.18$ (AUD) per pack

(1 pack can house 100 photographs)

30 packs @ $\$ 71.18$ a pack $=\$ 2,345.40$ (AUD)

\section{Prolong Archival Mounting Card (Natural), 15 Pack}

Order \#: PAMC-FC-N-25

Size: Foolscap $216 \times 330 \mathrm{~mm}$

Price: $\$ 12.73$ (AUD) per pack

(1 sheet makes $26 \times 8$ inch rigid supports)

22 packs @ $\$ 12.73$ each $=280.06$ (AUD)

\section{File Folders, 100 Pack}

Order \#: PFF-100 Folder

Size: Foolscap 240x355 mm

Price: $\$ 45.45$ (AUD) per pack

( 1 folder $=26 \times 8$ folders)

15 packs @ $\$ 45.45$ each $=\$ 681.75($ AUD $)$

\section{Total cost for materials $=\$ 3,465.21$ (AUD)}

Total cost for labour (one month) $=\$ 3,666.67$ (AUD)

\section{Option 4}

This option looks the most like the original current housing. This method puts them in the same cardboard boxes as options 2 and 3, but puts each record into paper envelopes. There are no separate housings for photographs or paper; they are stored together as they are currently. The only difference is that these materials are sturdier and of archival quality. All of these materials for this option are from Conservation Resources. 


\section{Advantages:}

- Opaque boxes and envelopes protect against UV radiation from light.

- Paper enclosures are porous, which protect the objects from accumulating moisture and harmful gasses. ${ }^{4}$

- The enclosures are easier to write the accession numbers on than the plastic enclosures.

\section{Disadvantages:}

- While paper materials are usually inexpensive, this is actually the most expensive form of housing. It is possible to look for cheaper envelopes at other suppliers, which also meet archival standards.

- The paper envelopes are opaque and therefore in order to view the photographs and particulars sheets, the housing must be removed; this increases chances of handling damage, such as abrasion.

- The intimate enclosure does not separate the acidic paper materials from the photograph, which will allow acid migration from the paper to the photograph.

\section{Materials:}

Prolong 500 year Archival Corrugated Boxes, 50 Pack

Order \#: Box 1-50

Size: $168 \times 371 \times 250 \mathrm{~mm}$

Price: $\$ 158.00$ (AUD) per pack

1 pack of 50 boxes $=\$ 158.00$ (AUD)

University Products Perma/Dur Envelopes, 100 Pack

Order \#: 381-7010

Size: $178 \times 254 \mathrm{~mm}$

Price: $\$ 115.00$ (AUD) per pack

30 packs @ $\$ 115.00$ each $=\$ 3,450.00$ (AUD)

Total cost of materials $=\$ 3,608.00$ (AUD)

Total cost of labour (one month) $=\$ 3,666.67$ (AUD)

\footnotetext{
${ }^{4}$ Ogden, 164.
} 
Housing Cost Analysis and Advantages/Disadvantages Assessment Tables

The following tables and outline the four housing proposals in two formats. One is a cost analysis of materials and the other displays the advantages and disadvantages of each option. These visual formats allow a quick comparison for State Records while it decides what housing proposal meets the needs of the collection and the abilities of the institution.

Table 8.1: Housing Cost Analysis

\begin{tabular}{cccc}
\hline Options & Materials & Labour & Approximate Total Cost \\
\hline$\# 1$ & $\$ 2,615.70$ & $\$ 3,666.67$ & $\mathbf{\$ 6 , 2 8 2 . 3 7}$ \\
$\# 2$ & $\$ 1,676.17$ & $\$ 7,333.34$ & $\$ 9,009.51$ \\
$\# 3$ & $\$ 3,465.21$ & $\$ 3,666.67$ & $\$ \mathbf{1 3 1 . 8 8}$ \\
$\# 4$ & $\$ 3,608.00$ & $\$ 3,666.67$ & $\mathbf{\$ 7 , 2 7 4 . 6 7}$
\end{tabular}

Table 8.2: Advantages/Disadvantages Assessment

\begin{tabular}{ccccc}
\hline Advantages & $\# 1$ & $\# 2$ & $\# 3$ & $\# 4$ \\
\hline high UV protection & & & & $\mathrm{x}$ \\
protects from handling damage & $\mathrm{x}$ & $\mathrm{x}$ & $\mathrm{x}$ & \\
Separates the photo from paper & $\mathrm{x}$ & $\mathrm{x}$ & $\mathrm{x}$ & \\
rigid backing & & $\mathrm{x}$ & $\mathrm{x}$ & \\
protects against pollutants & $\mathrm{x}$ & $\mathrm{x}$ & $\mathrm{x}$ & \\
porous (releases moisture/gases) & & & & $\mathrm{x}$ \\
materials supplied by local vendor & $\mathrm{x}$ & & & \\
\hline Disadvantages & $\# 1$ & $\# 2$ & $\# 3$ & $\# 4$ \\
\hline low melting point & $\mathrm{x}$ & $\mathrm{x}$ & $\mathrm{x}$ & \\
Requires removal for viewing & & $\mathrm{x}$ & $\mathrm{x}$ & $\mathrm{x}$ \\
Ferrotypes in high humidity & $\mathrm{x}$ & $\mathrm{x}$ & $\mathrm{x}$ &
\end{tabular}

\section{Long Term Goals $(5+$ years $)$}

1. The WWI collection should undergo digitisation in order to add digital images to the web catalogue.

The WWI portrait collection is currently not digitised and there are no plans for digitisation. However, due the nature of the collection and the constant abuse it sustains from handling, a digitisation project would be an ideal long-term goal. The digital images can be placed as low-resolution files online to aid in searching. This protects the reproduction services at State Records by making the digital images too small to print from home. 
The master files from digitisation should be stored as high resolution .TIFF files for reproduction purposes. By storing master files, these photographs will be saved from damage that is caused by making reproductions. Instead of making a reproduction from the original, the digital file can be opened and copies printed from it. Photocopying the photograph causes deterioration from light and handling each time. Using the digital file causes no harm to the original photograph, other than when the orginal file is created.

However, before undergoing a costly and time consuming project, assessments must be made about the current facilities at State Records to preserve and store digital files. If there is not enough memory available to store the files or back-ups, or the proper materials to digitise the photographs, then plans are needed to allocate funds to the digitisation plan. There also need to be trained staff members who are able to digitise the entire collection.

There also needs to be consideration about creating back-ups and constantly upgrading both hardware and software as technology shifts and becomes obsolete. This requires State Records to be diligent in keeping its digital files compatible with current technology in order to preserve them. This will require additional funds; approximately $14 \%$ to $60 \%$ of the original costs used to convert the collection will be needed to maintain the digital images. ${ }^{5}$ This should be taken into account when drawing up a plan for digitisation. The preservation of digital media is outside the scope of this survey, but must not be overlooked by State Records when digitising the WWI collection. Consulting other institutions, such as National Archives or the State Library of South Australia, who already have strong preservation programs in place for digital media, is highly recommended. As with the original photographs, digital files must be preserved over time.

\section{The web catalogue should be assessed for completeness.}

Once the digitisation process is complete, the web catalogue should undergo assessment about how closely it matches the original particulars sheet. Information unavailable on the web catalogue should be added so it is searchable for researchers, who may want to know details about soldiers outside of the few categories available online. For example, there is no way to search place of birth or even the additional notes where it might list where the soldier died. A researcher looking for soldiers who died in France would not be able to pull records from the web catalogue because the information is omitted. These details could benefit both scholars and family historians while trying to locate photographs within the collection. This additional information paired with digital images would allow researchers unable to travel to State Records to search the collection for valuable information. Adding the missing information from the particulars sheets also ensures that the information will still be available if the sheets deteriorate past recognition.

\footnotetext{
${ }^{5}$ Vogt-O'Connor, "Planning Digital Projects for Preservation and Access," Conserve O Gram 19/21 (2000): 4 .
} 


\section{Chapter 9}

\section{Conclusion}

This report draws attention to the urgent need for better preservation practices surrounding the World War I Portrait collection at State Records of South Australia. In order to ensure that the collection will be available for future generations, steps must be taken to improve State Records's preservation techniques. This collections care proposal is not the only plan of action that can be taken, but based on the evidence that I have gathered from the conservation survey and condition report, they are some of the most important measures that should be taken in order to benefit the collection. As the collection stands currently, its housing is ineffectual and the arrangement confusing.

There were some difficulties that I encountered in my research for this thesis project. My original condition report had sixteen different categories of deterioration for the photographs, which I found to become extremely time consuming. It was quicker to combine similar forms of deterioration into broader categories to get a better idea of the overall state of the photograph, instead of minute details. It was also ineffectual to measure each individual photograph once I had established that the largest the photograph could be was $6 \times 8$ inches. Instead, I changed the measurements so I could note when a photograph was mounted or un-mounted and whether or not it was a cabinet card or a postcard. As I worked, I realized that the format was more important than the size. If they were not one of those two specialty photographs, then the size of the photograph would vary dramatically. As long as I knew the maximum size possible for each object, I could estimate the approximate cost of materials for re-housing the entire collection.

There were also pitfalls to the conservation survey. I had not prepared the staff at State Records enough for my visit, so when I had specific questions about the filtration system or a back-up generator, they could not answer these questions. This required me to do extra research, such as contacting the contractor; in the end, I was still unsuccessful in obtaining the specific information I needed. This has proven that the preparation that goes into making a site visit is crucial, because without it, the institution may very well be unprepared to answer the necessary questions. I also could have benefited from bringing equipment to measure the lux levels inside the repository; even though the lights are on timers, staff members are constantly in and out causing the lights to be left on for prolonged periods. 
Creating new housing proposals was difficult due to the nature of the collection. Since each photograph is accompanied by a particulars sheet, traditional housings would not work. If the collection is re-housed, the objects have to remain together in order to maintain the integrity of the collection. Many of the records also contained other miscellaneous items such as letters and memorial cards that need to stay with the record. Multiple items meant that there had to be several types of housing in order to keep them together, while leaving them in better condition than they are currently. This of course created a more costly housing plan than if I needed to create housing for only 2,960 photographs and nothing else. The solutions I created have some flexibility to them, but also take into account that the objects must stay together and yet isolated from each other within their housings. I considered the photographs the highest priority for separate intimate enclosures; they need their own housings to protect them from acid migration from papers and against handling damage.

Through this practical project, I was able to bring to the attention of State Records issues that must be dealt with, such as the film stored with other mixed media. If allowed to continue in the present state, the housing will continue to provide little protection against handling damage. The current housing will eventually deteriorate to a point where it provides absolutely no protection for the photographs. In fact, they will begin to exacerbate deterioration rather than protect against it. The report from the survey as well as the collections care proposal are meant to aid State Records in allocating the proper staff, funding and other resources needed to ensure the collection will survive for future researchers. This is a collection rich in South Australian history, rich in the history of studios and photographers, the culture of photography at the beginning of the 20th century, the impact of war on lives and the desire of past generations to preserve the photographic memory of their loved ones for the future. To let it fall into disrepair by bad preservation would not only contradict the State Records Act 1997, but also to deny the collection's importance to researchers today. 


\section{Bibliography}

Carrier. "Air Handling Units Product Information." http://eto. carrier. com/litterature/psd/13903.pdf.

Casella, Luisa. Photograph Collections Survey: Guidelines Proposal. Rochester, NY: Advanced Residency Program in Photograph Conservation, 2007.

Casella, Luisa, and Rosina Herrera. Hispanic Society of America: Survey Report. Rochester, NY: Advanced Residency Program in Photograph Conservation, 2007.

Dudley, Dorothy H., and Irma Bezold Wilkinson. Museum Registration Methods. Washington, D.C.: American Association of Museums, 1979, 3rd edition.

Hoyle, Alison. Ancestors in Archives: A Guide for Family Historians to South Australia's Government Archives. South Australia: State Records of South Australia, 2000.

Ogden, Sherelyn, editor. Preservation of Library and Archival Materials: A Manual. Andover: Northeast Document Conservation Center, 1994.

O'Reilly, Priscilla, and Allyn Lord. Basic Condition Reporting: A Handbook. New York: Southeast Registrars Association, 1988, 2nd edition.

Reilly, Bernard F., James M. Reilly, Debbie Hess Norris, Steven T. Puglia, Paula De Stefano, Julia Van Haaften, and Patricia McClung. Photograph Preservation and the Research Library. Mountain View: The Research Libraries Group, 1991.

SRSA. "State Records Act.", 1997.

. "State Records of South Australia.", 2003-2008. www.archives.sa.gov.au/.

Tuttle, Craig A. Ounce of Preservation: A Guide to the Care of Papers and Photographs. Highland City: Rainbow Books, 1995.

Valverde, Maria Fernanda. Photographic Negatives: Nature and Evolution of Processes. Rochester, NY: Adavanced Residency Program in Photograph Conservation, 2005, 2nd edition.

Vogt-O'Connor, Diane. "Planning Digital Projects For Preservation and Access." Conserve O Gram 19, 21. 
Wolf, Sara. "The Conservation Assessment: A Tool for Planning, Implementing, and Fundraising.", 1998. www.heritagepreservation.org/PDFS/2002g.pdf. 


\section{Appendix A}

\section{Call for Donations Poster, 1918}

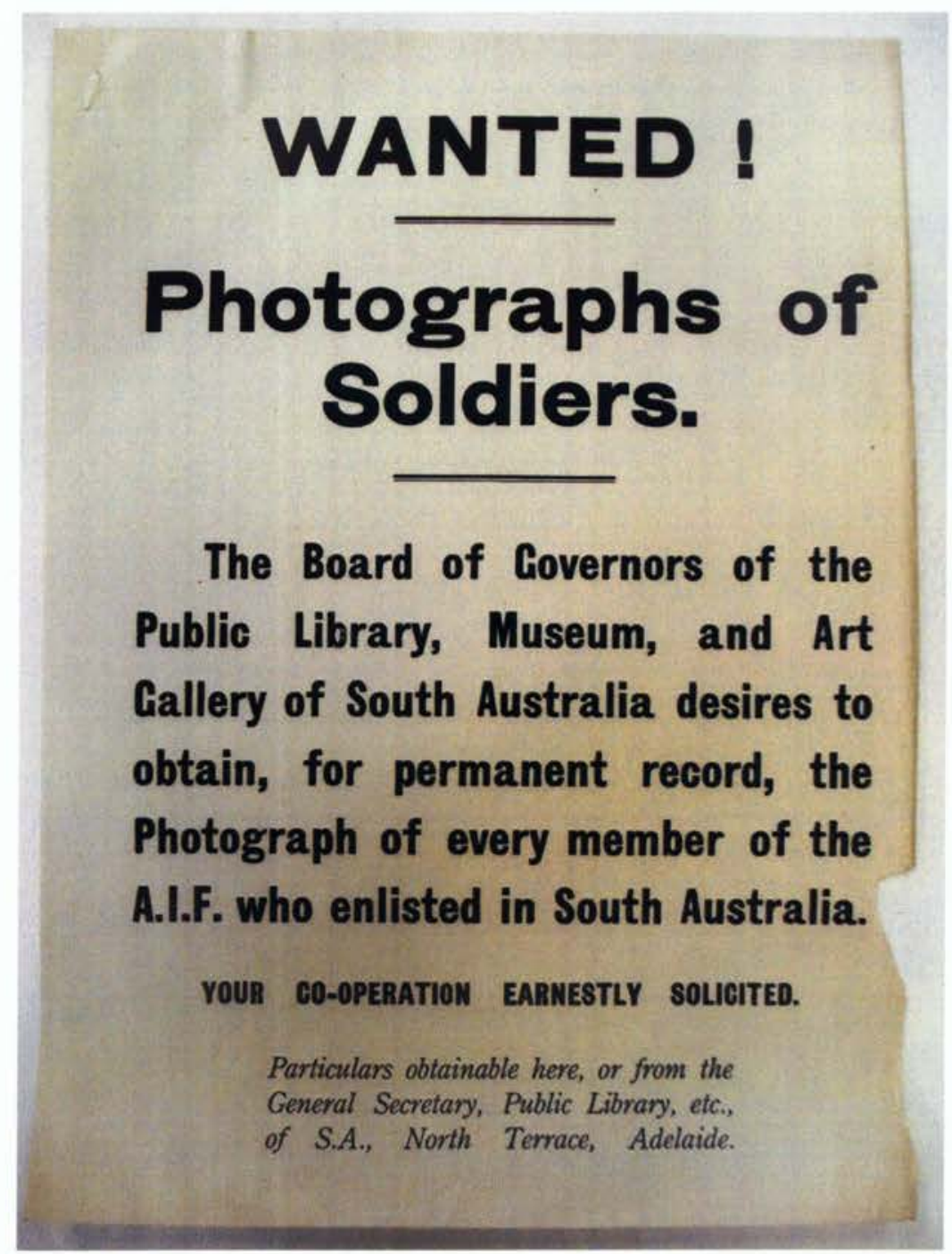




\section{Appendix B}

\section{Call for Donations Circular, 1918}

Public Library, ftluseum and art Gallery of auth Australia.

PHOTOGRAPHIC RECORD OF SOUTH AUSTRALIA.

PRESRRVING SOLDIRRS PHOTOGRAPHS

The Board of Governom of the Puldic Library, Maseam, and An Gallery have, for nome year: collected photographr of old beildings in and arvund Adelaide. Photographic groupe of old calonists are alwo preserved in the Public L,ibrary, and are of wever ceasing interest to visiton. It has now been decided to collect photographs of South Auntralian soltiens in uniform who have entisted for the great Faropean war. It is believed that it will be recognied by all that to be represented it this nationai collection-which will be for all time the permacent relerence collection of the State-will be a coveted privilege, and that, for fatafe generations, it will have as great, if not greater intereat than for the people of to-day. This photographic recond would be of littie aue writhoat perticalan cosconaing each soldier. and to secure a place in the record a form must be filled up supplying the following detsils :-Full mame. dates of birth and of ealiatment, tank, number, battalion, and distipctions.

All soldiers and relatives of soldien are invited to help to make this record a representative and worthy collection for permenet poblic releresce, by forwardipg photographs of soldiens with the parricalan of ideatity anked for. Do it now ! The longer you delay, the more diffecalt it will be to fiot the photograph.

All photograpbs, abd all correnpondenor relatiog to this matter should be addrosied to the Generat Secretary. Public Library, Musum, asd An Gallery of Sonth Anstralia, Adelaide.

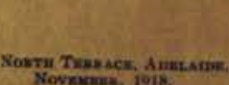

J. k. 6. ADAMS,

Geskesh SEcoktass.

Nowneme, inis:

Public t.ibrers, Nurcuan, and 


\section{Appendix C}

\section{Examples from GRG26/5/4}

Particulars for 2533

Full Name (Surname First): Smith, Lester Bryce

Date of Birth: 22 November 1893

Date of Enlistment: 17th January 1916

Trade or Calling: Clerk

Born in or near what town: Adelaide

Address Prior to Enlistment: 7 East Terrace, Mile End

Rank, Number: 6580, Private

Battalion, Distinctions: 21/10th Battalion

Donor Name: W.D. Smith

Donor Address: 7 East Terrace, Mile End

Additional Notes: Wounded at Dunecourt 8 May 1917

Killed in action at Shazeele, France 12 May 1918

\section{Particulars for 2949}

Full Name (Surname First): Vincent, Harold

Date of Birth: 11 May 1896

Date of Enlistment: 22 May 1913

Trade or Calling: Electrician

Born in or near what town: Adelaide

Address Prior to Enlistment: Hughes St. Mile End, South Aus.

Rank, Number: 2959 A.B. (Seaman Torpedoman)

Battalion, Distinctions: Royal Australian Navy

Donor Name: H. Vincent

Donor Address: 14 Third Avenue, Alberton East

Additional Notes: none 

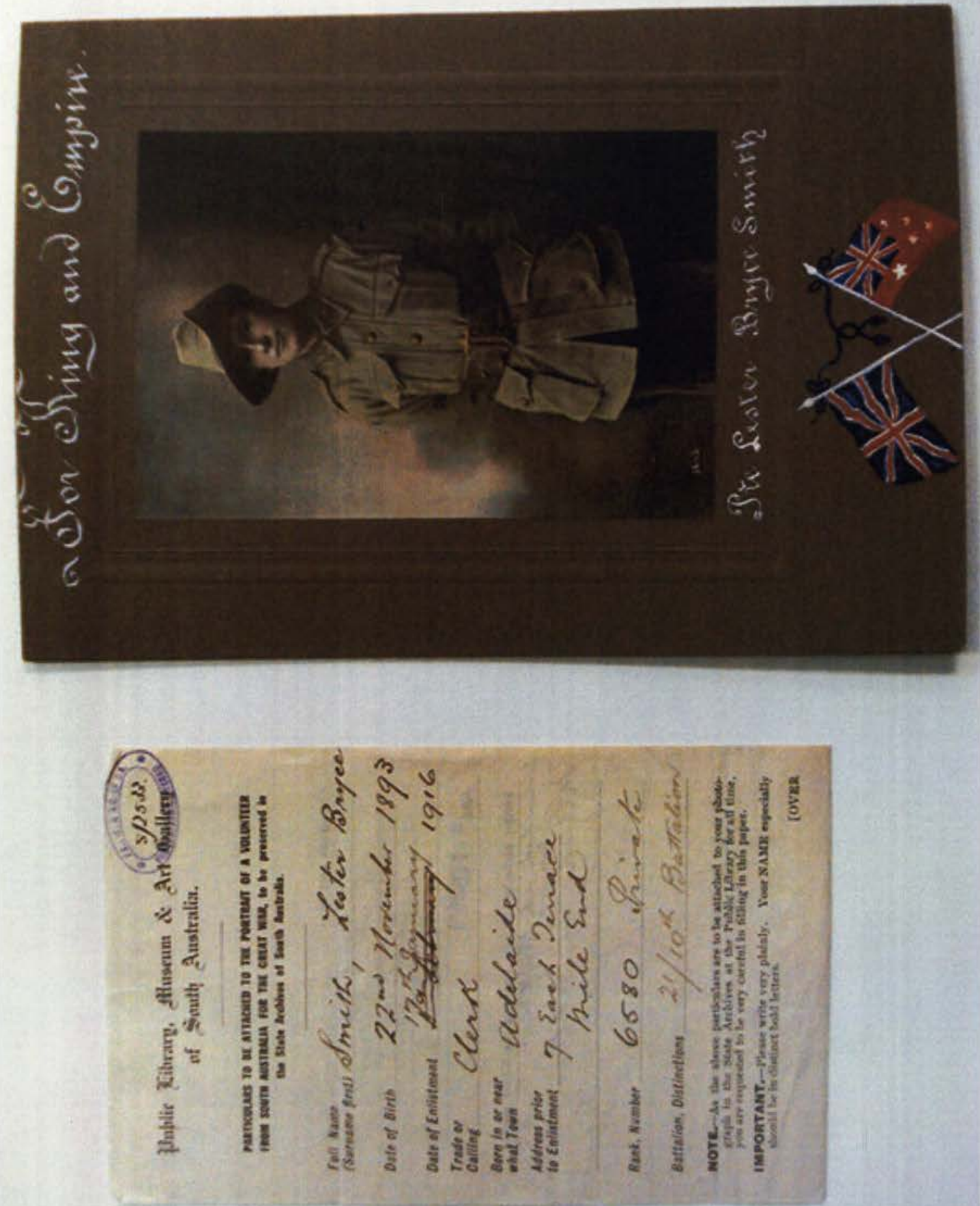

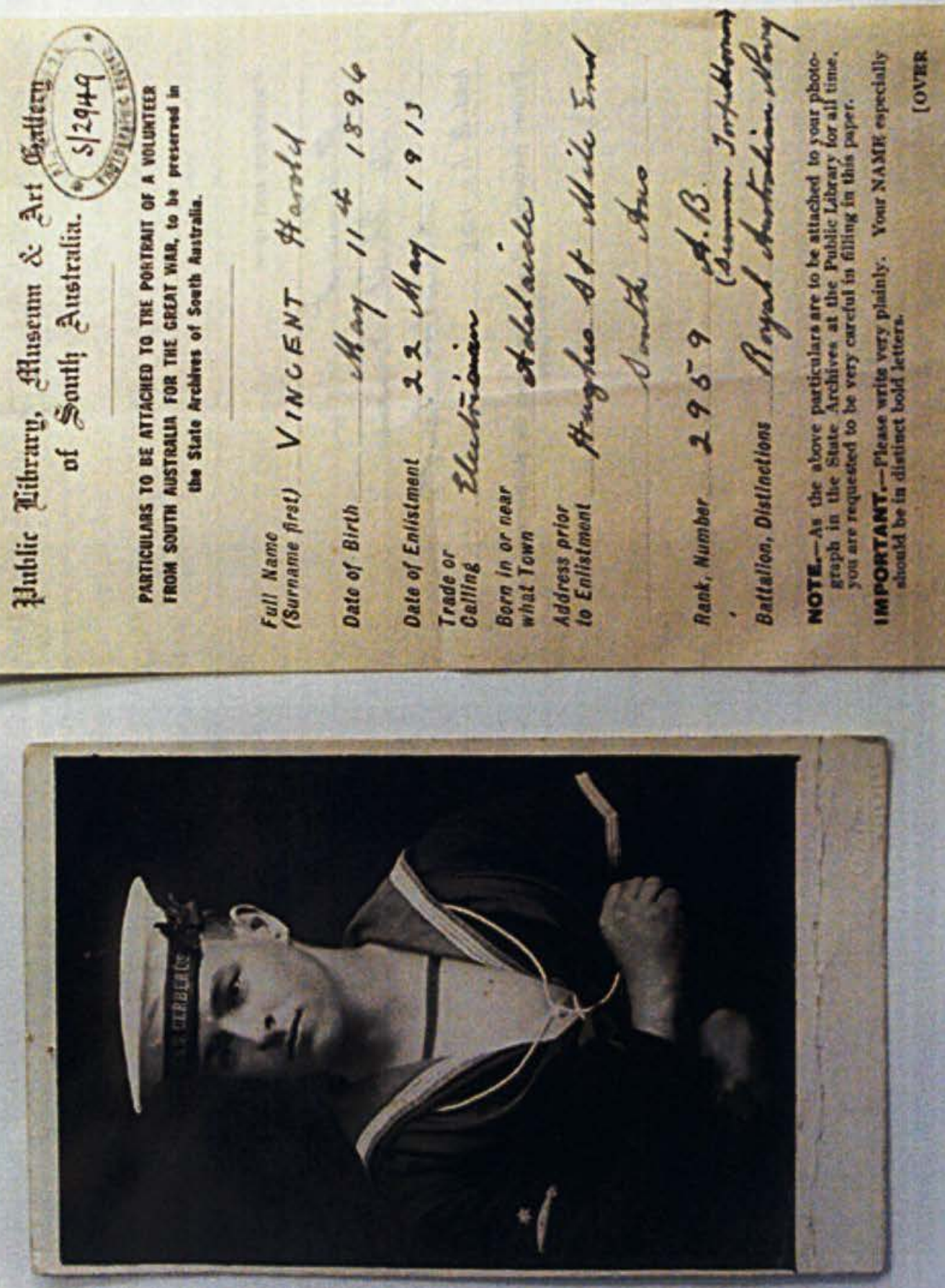


\section{Appendix D}

\section{GRG26/5/4/1370 and Examples of Letters Included}

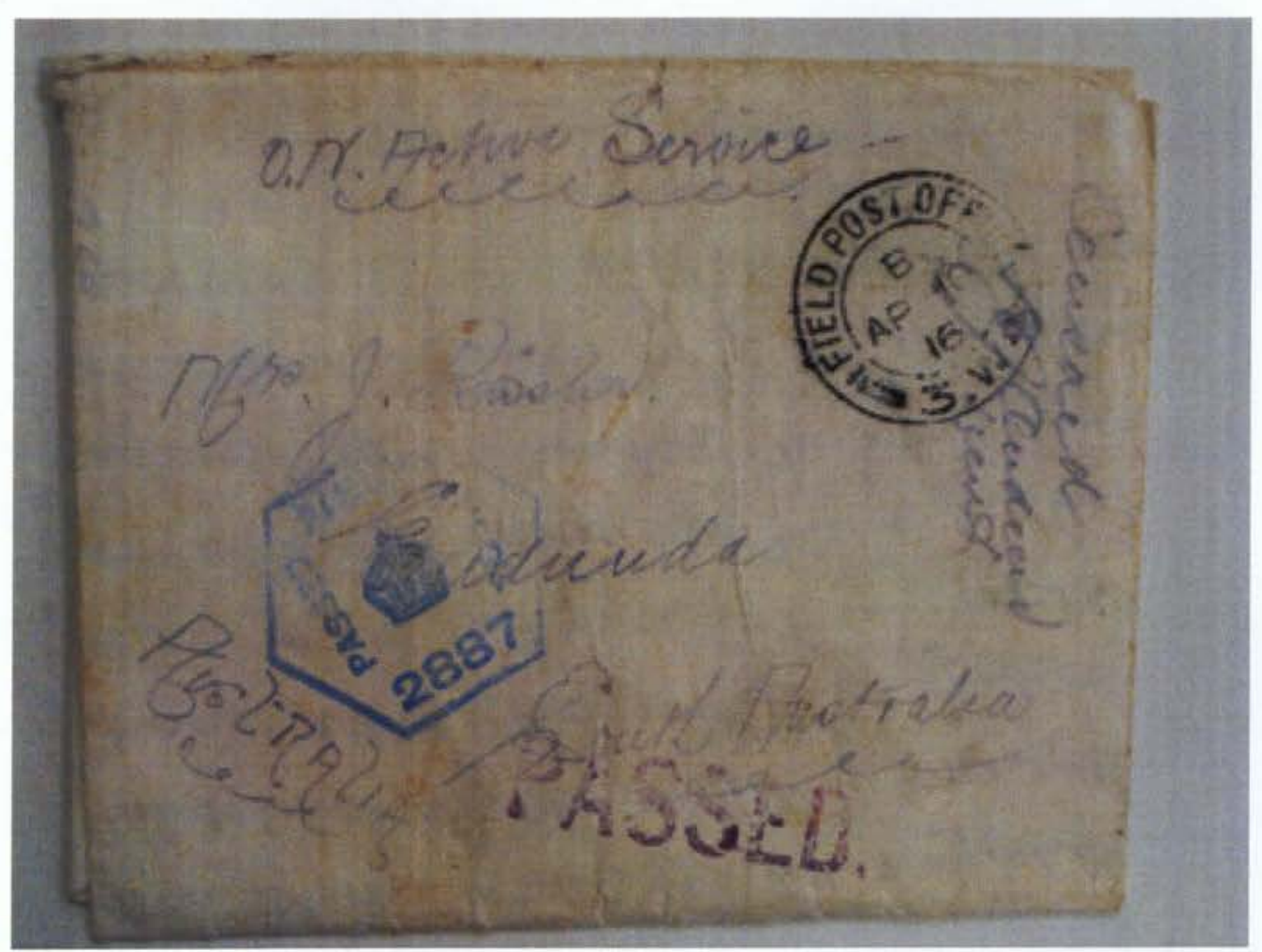

Envelope from 1370 

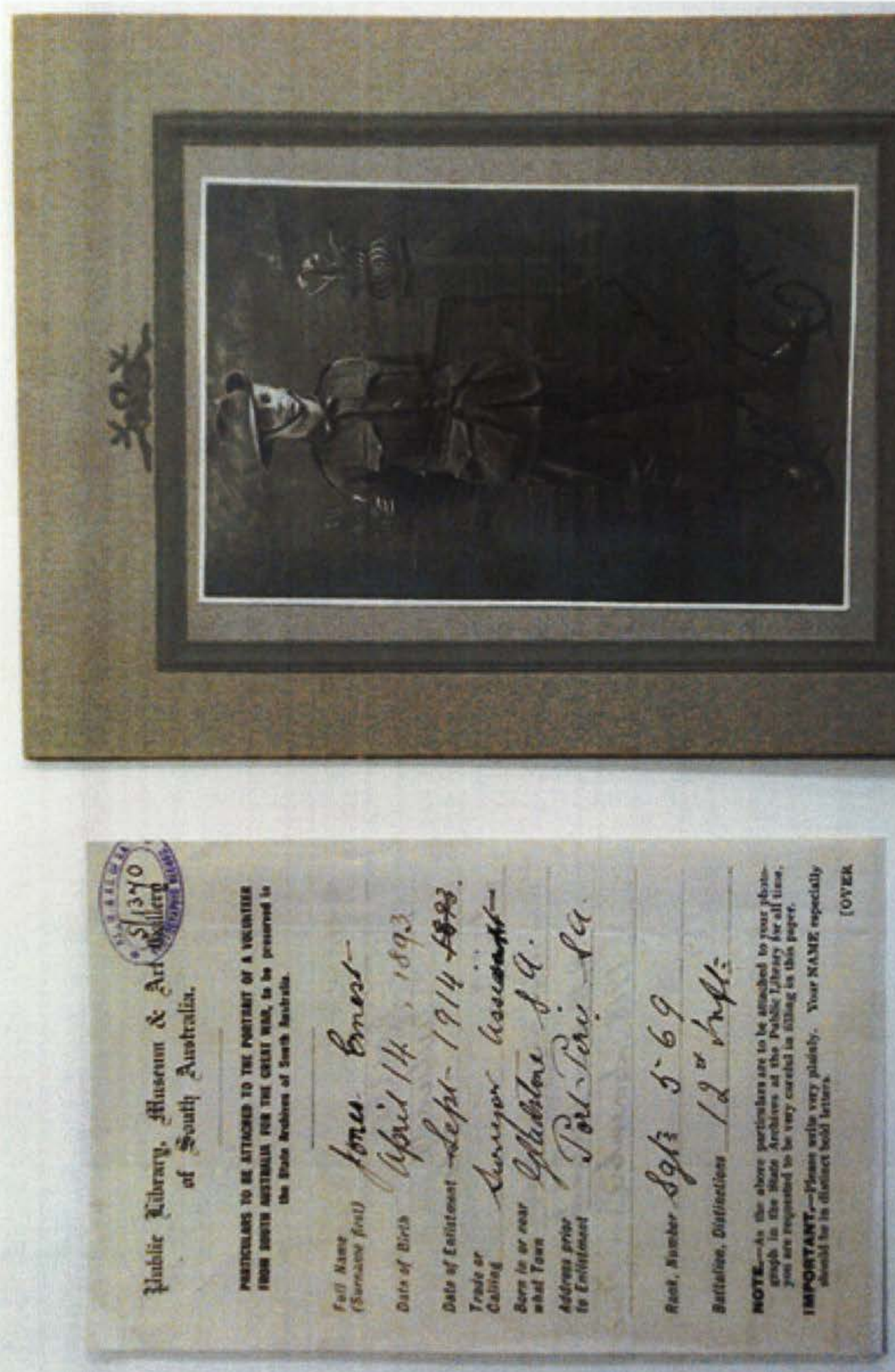

Photograph 1370 


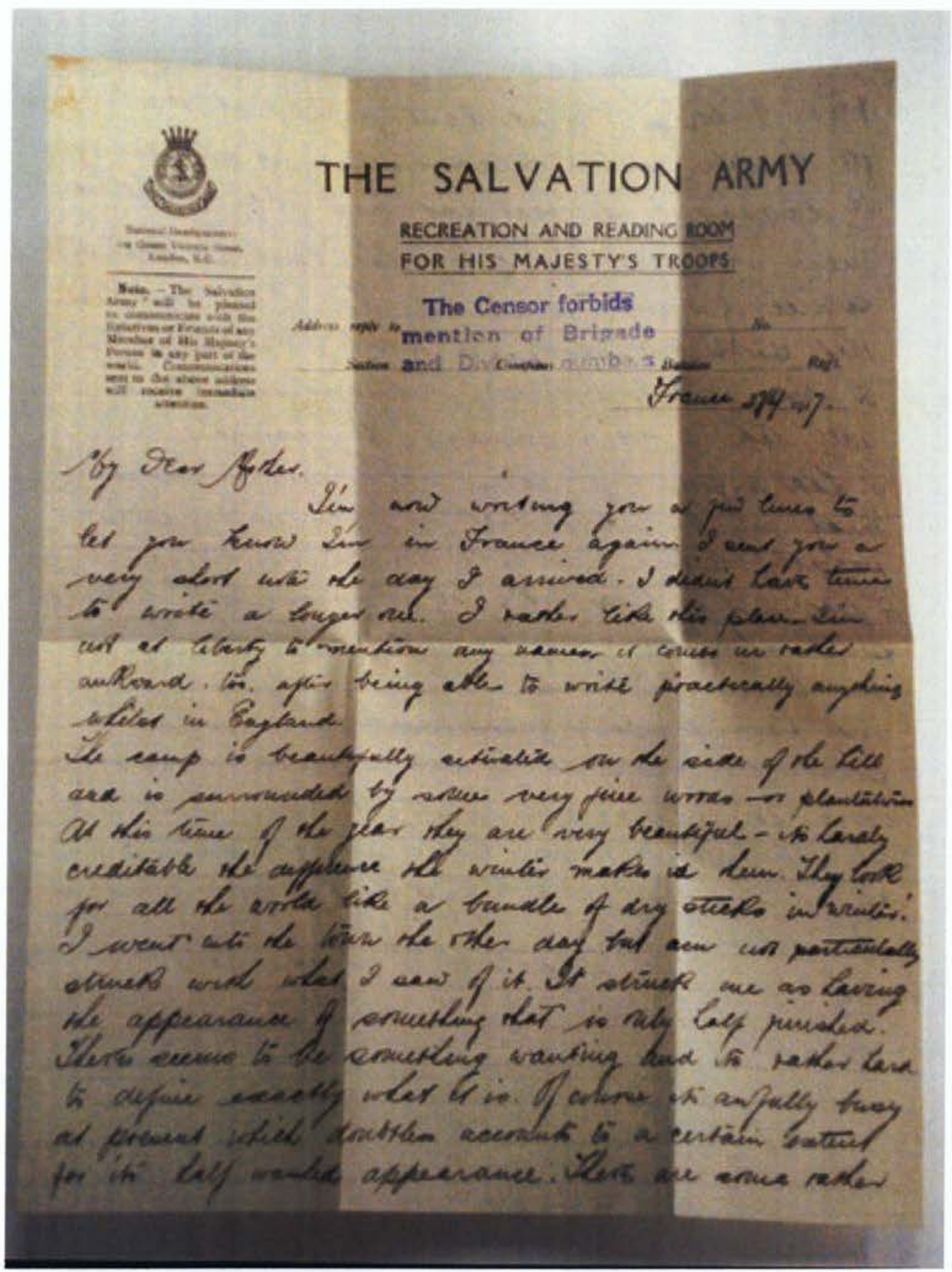

Letter from France, 1917 


\section{Appendix E}

\section{Chart of Retrieval Requests from 2004 to 2008}

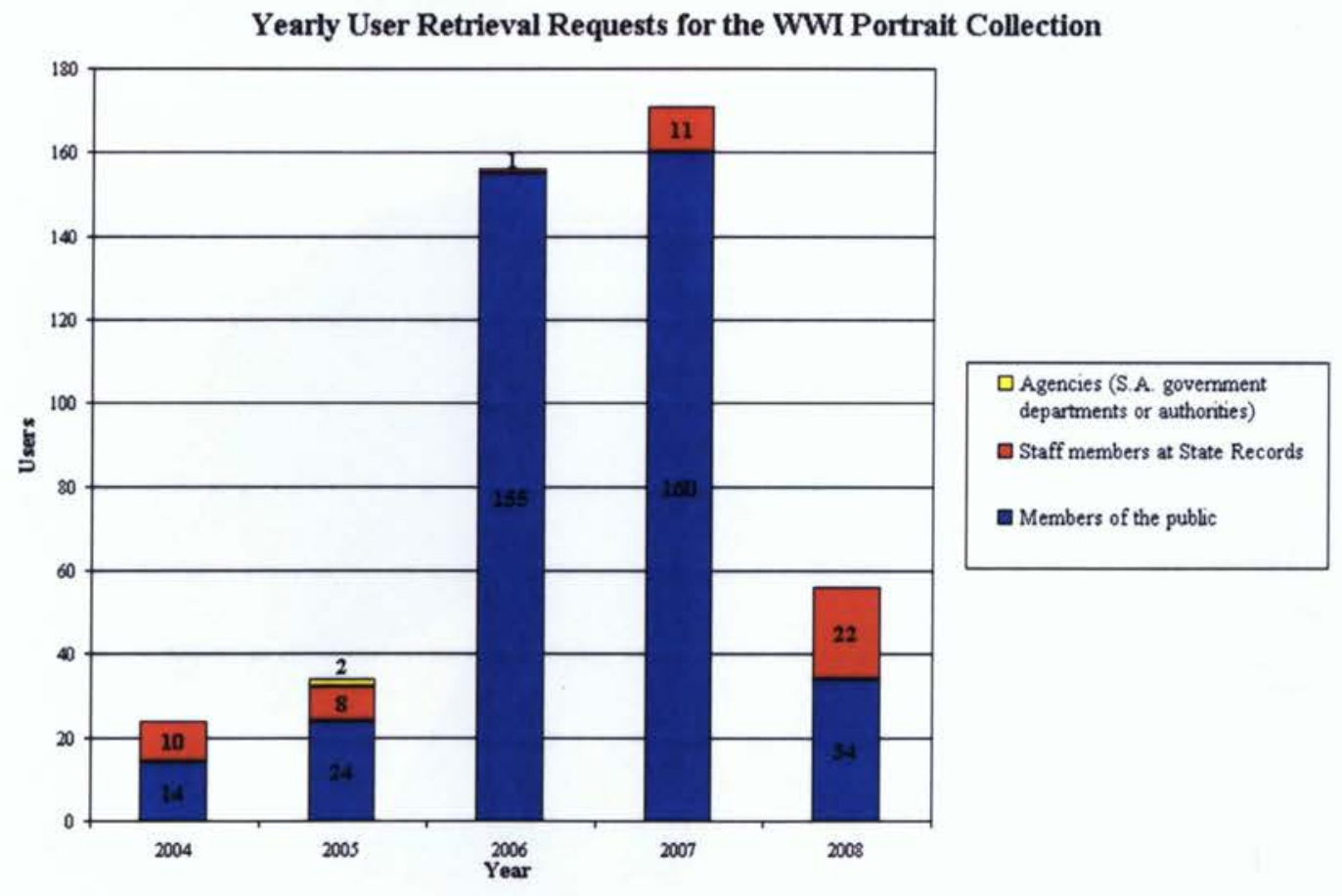




\section{Appendix F}

\section{Chart of Photographic Formats Found in the Sample}

Format of Photographs in WWI Portrait Collection

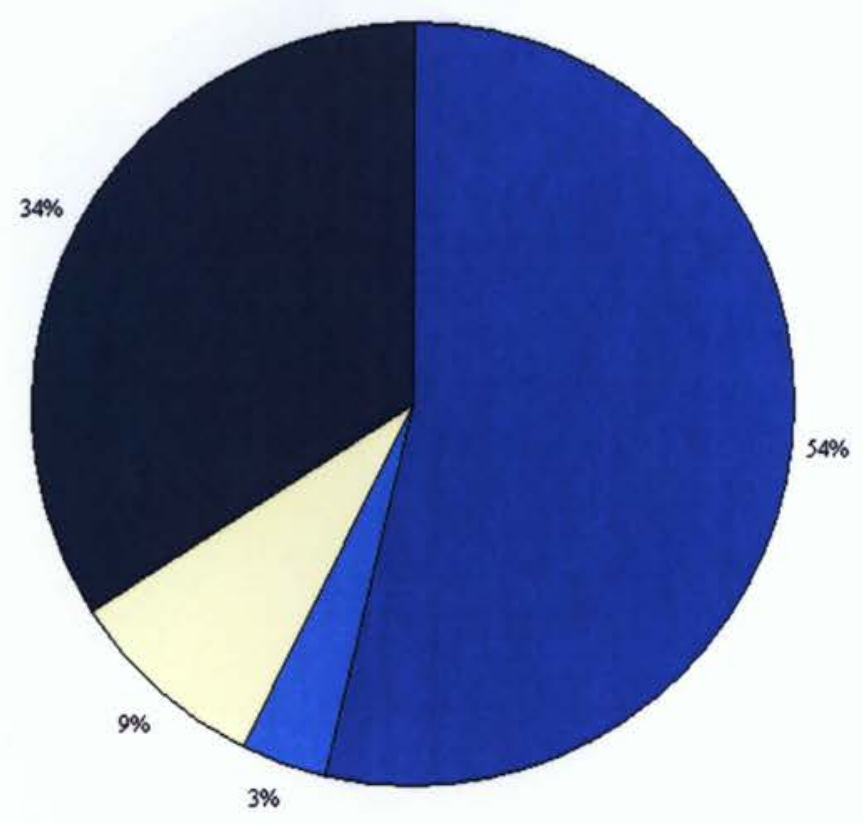

Mounted

unmounted

$\square$ Cabinet Card

- Postcard 


\title{
Appendix G
}

\section{Charts Showing Most Common Types of Deterioration by Box}

\author{
Box 1 Condition Results
}
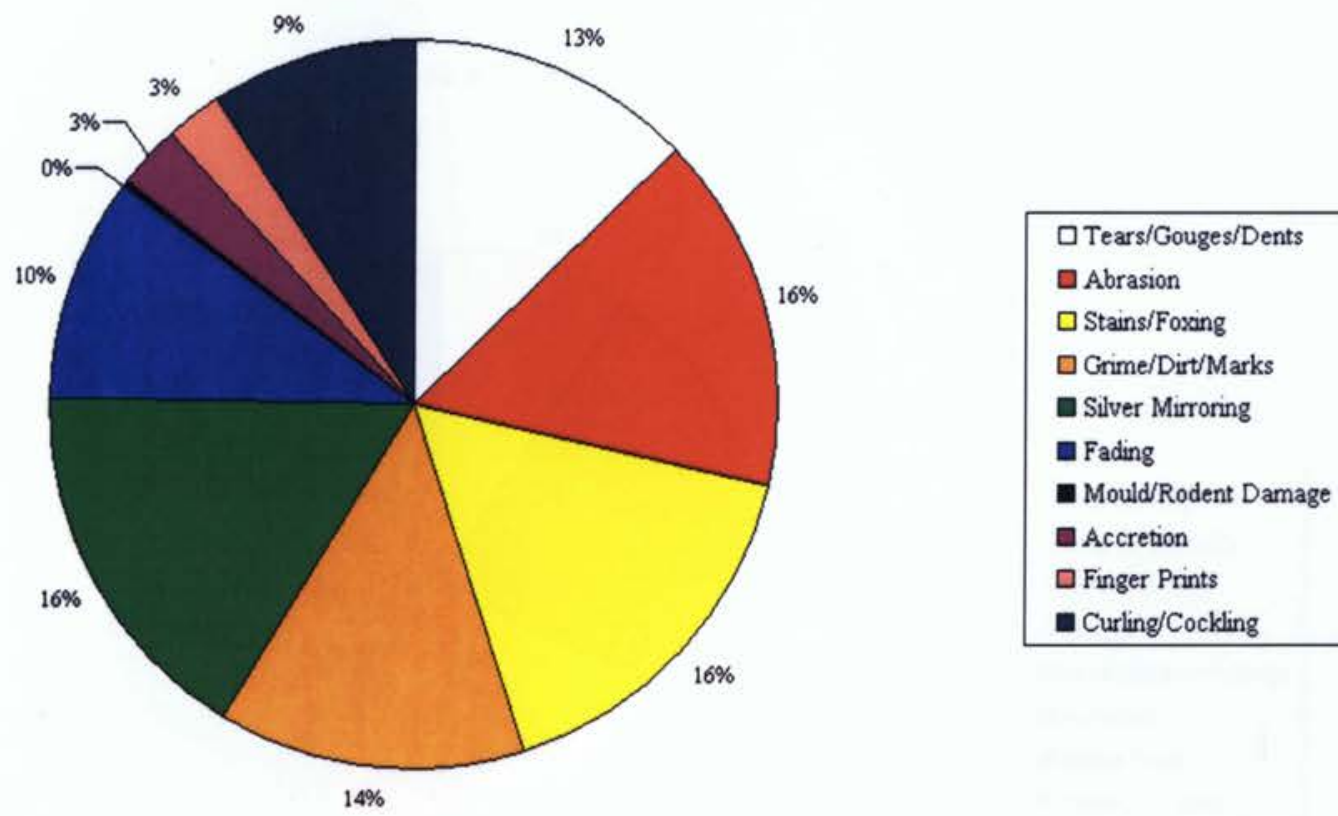


\section{Box 2 Condition Results}

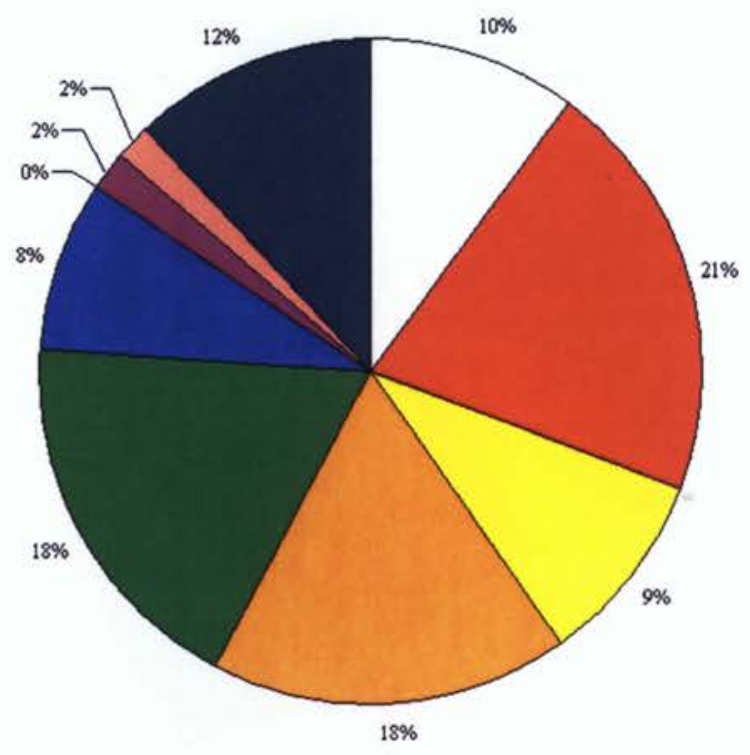

Box 3 Condition Results

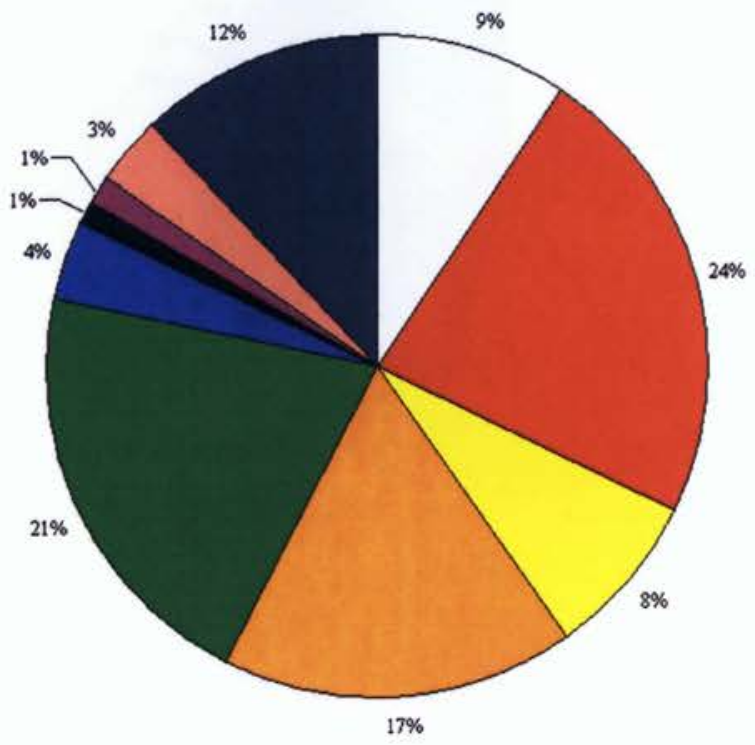

口Tears/Gouges/Dents

Abrasion

$\square$ Stains/Foxing

口 Grime/Dirt/Marks

- Silver Mirroring

E Fading

- Mould/Rodent Damage

- Accretion

$\square$ Finger Prints

- Curling/Cockling $\square$ Tears/Gouges/Dents

$\square$ Abrasion

口 Stains/Foxing

口 Grime/Dirt/Marks

- Silver Mirroring

- Fading

- Mould/Rodent Damage

accretion

$\square$ Finger Prints

- Curling/Cockling 
Box 4 Condition Results

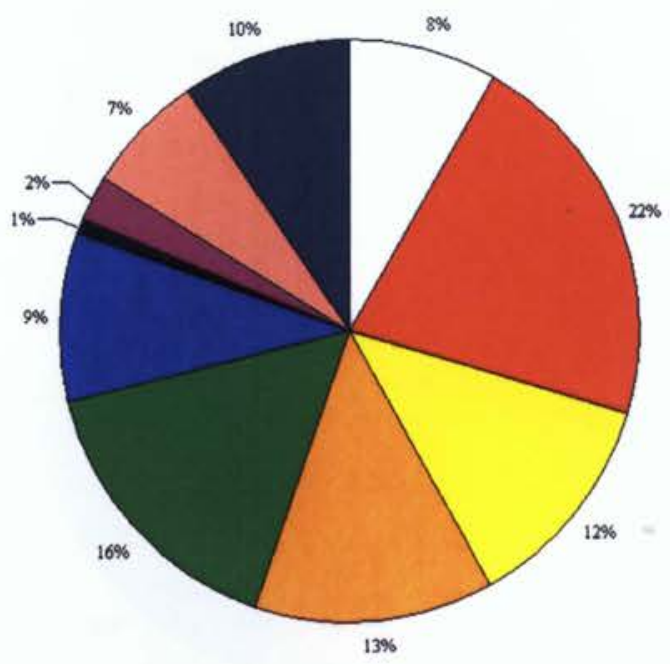

$\square$ Tears/Gouges/Dents

a Abrasion

口 Stans/Foxing

口 Crime/Dirt/Marks

- Silver Mirroring

a Fading

- Mould/Rodent Damage

accretion

$\square$ Finger Prints

a Curling/Cockling

\section{Box 5 Condition Results}

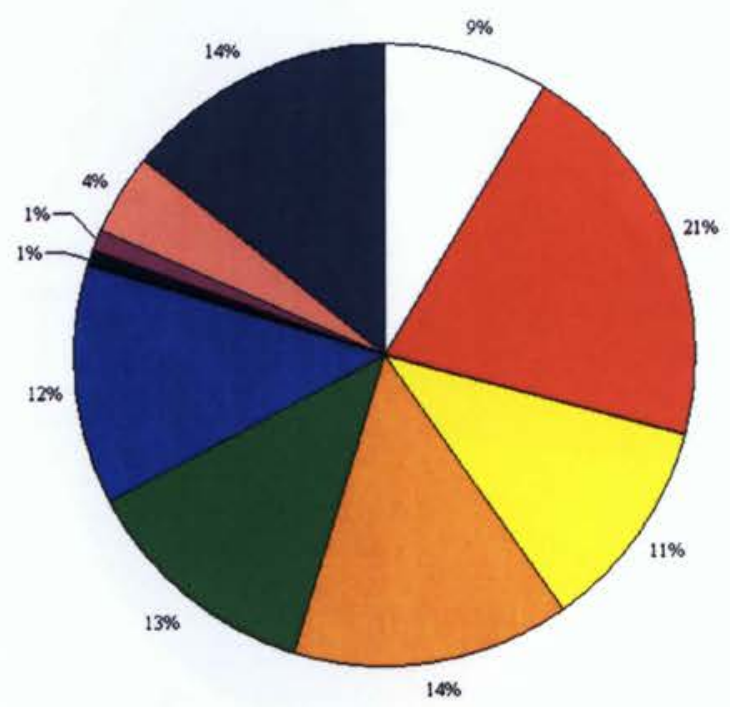

$\square$ Tears/Gouges/Dents

abrasion

口Stains/Foxang

$\square$ Grime/Dirt/Marks

- Silver Mirroring

- Fading

- Mould/Rodent Damage

accretion

$\square$ Finger Prints

- Curling/Cockling 


\section{Box 6 Condtion Results}

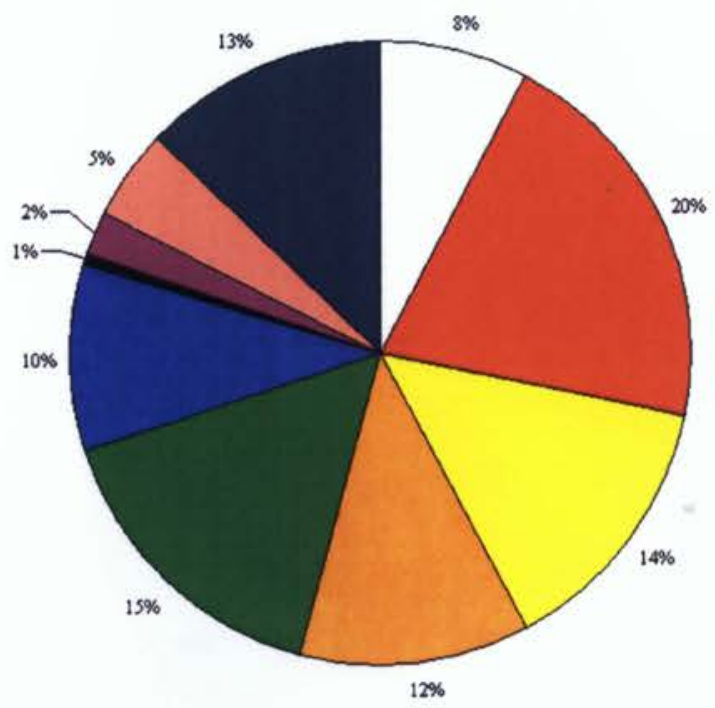

$\square$ Tears/Gouges/Dents

abrasion

口Stains/Foxing

$\square$ Gnime/Dirt/Marks

- Silver Mirroring

a Fading

- Mould/Rodent Damage

accretion

$\square$ Finger Prints

- Curling/Cockling

Box 7 Condition Results

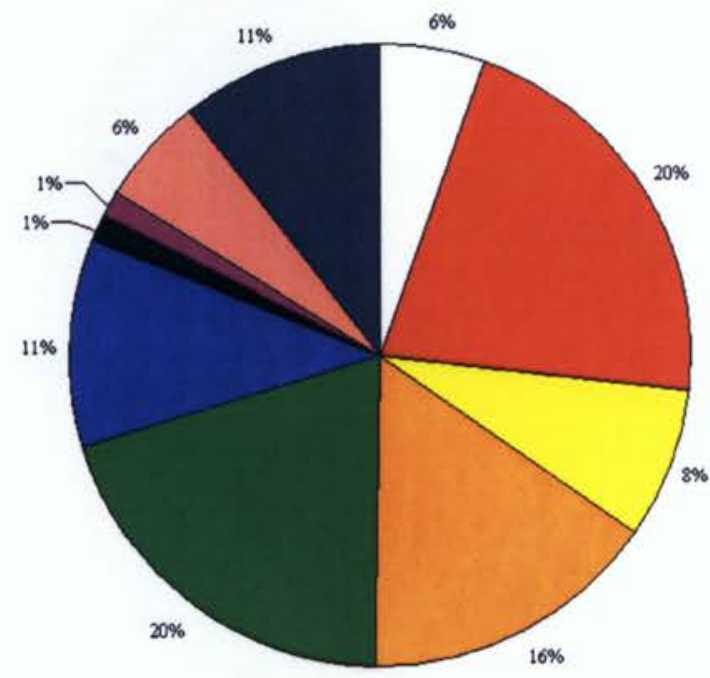

口Tears/Gouges/Dents

- Abrasion

口Stains/Foxing

口 Grime/Dirt/Marks

- Silver Mirroring

- Fading

would/Rodent Damage

accretion

a Finger Prints

- Curling/Cockling 


\section{Box 8 Condition Results}

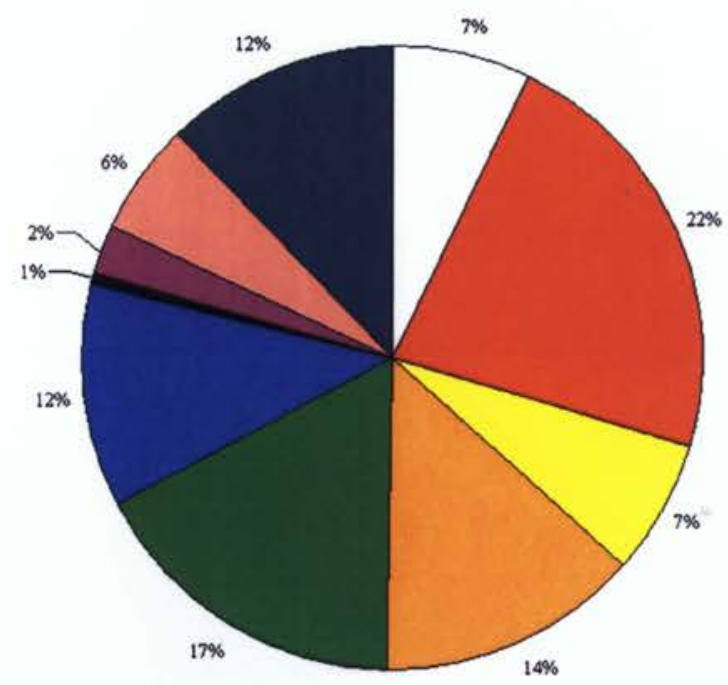

口Tears/Gouges/Dents abrasion

$\square$ Stains/Foxing

口 Grime/Dirt/Marks

- Silver Mirroring

- Fading

- Mould/Rodent Damage

accretion

$\square$ Finger Prints

- Curling/Cockling

Box 9 Condition Results

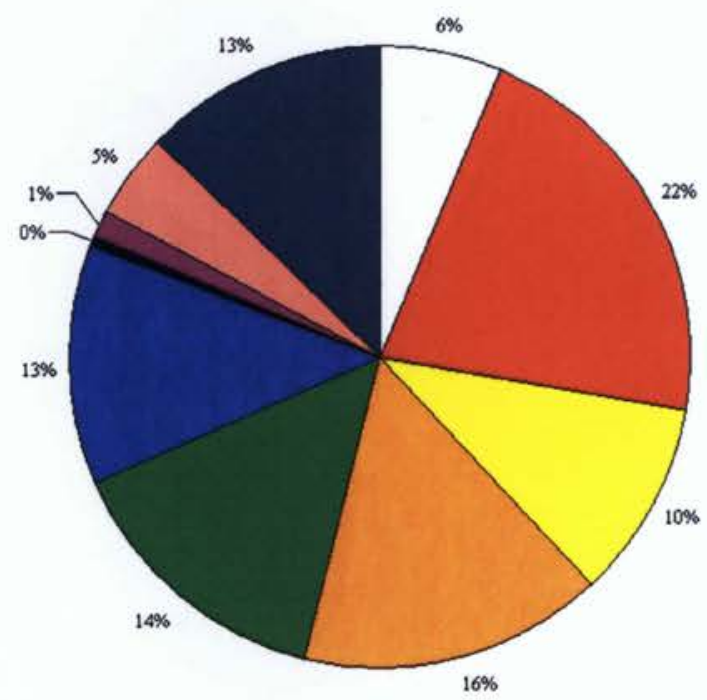

$\square$ Tears/Gouges/Dents

a Abrasion

口 Stains/Foxang

口 Grime/Dirt/Marks

- Silver Mirroning

a Fading

- Mould/Rodent Damage

- Accretion

口 Finger Prints

- Curling/Cockling 
Box 10 Condition Results

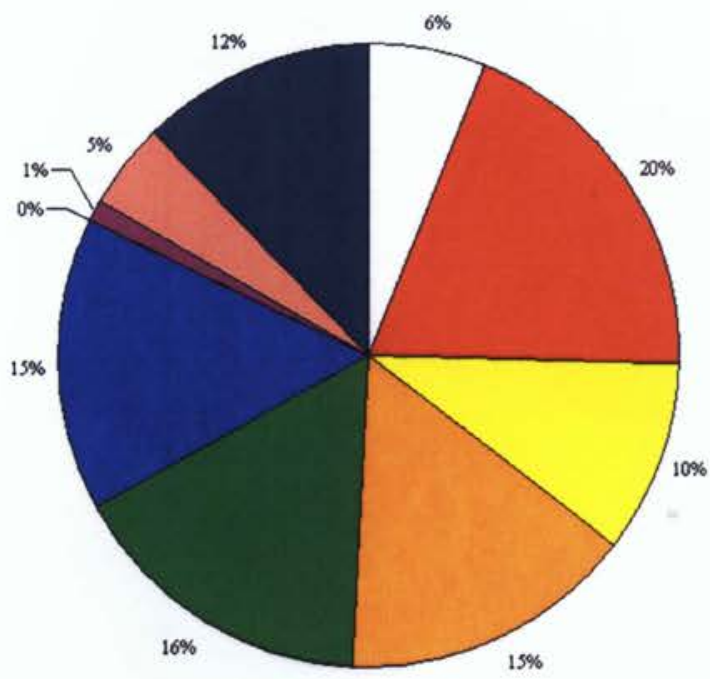

$\square$ Tears/Gouges/Dents

- Abrasion

口Stains/Foxing

口 Grime/Dirt/Marks

- Silver Mirroring

- Fading

- Mould/Rodent Damage

- Accretion

口 Finger Prints

- Curling/Cockling

\section{Box 11 Condition Results}

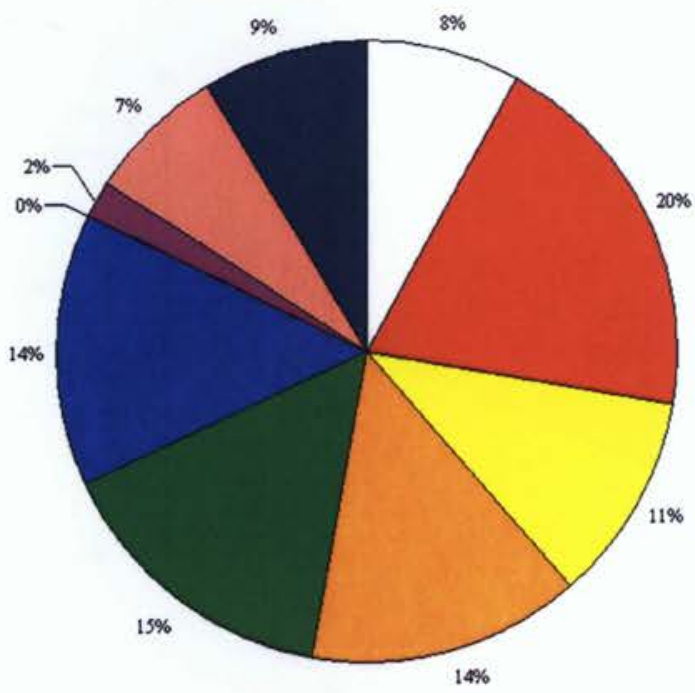

$\square$ Tears/Gouges/Dents

abrasion

口 Stains/Foxaing

口 Grime/Dirt/Marks

a Silver Mirroring

a Fading

a Mould/Rodent Damage

accretion

口 Finger Prints

- Curling/Cockling 
Box 12 Condition Results

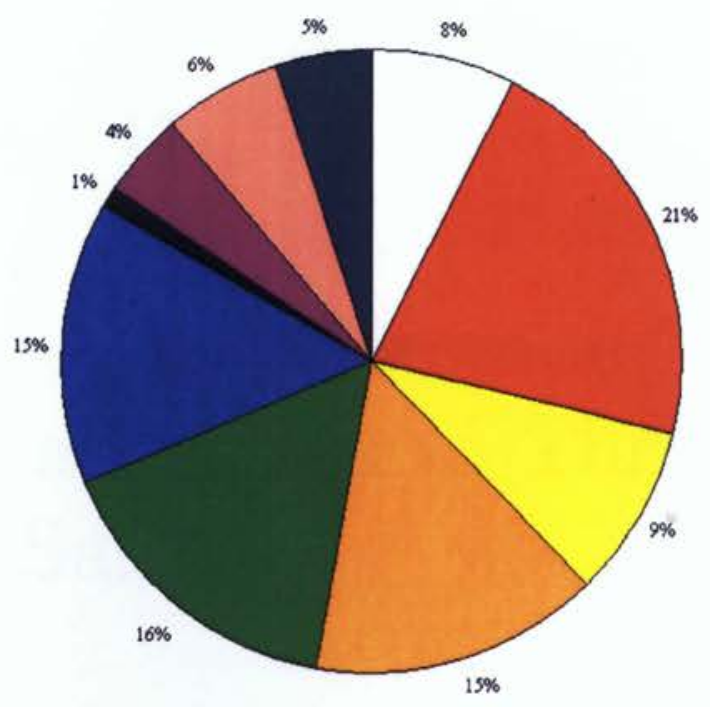

$\square$ Tears/Gouges/Dents

$\square$ Abrasion

$\square$ Stains/Foxing

$\square$ Grime/Dirt/Marks

- Silver Mirroring

- Fading

- Mould/Rodent Damage

accretion

$\square$ Finger Prints

- Curling/Cockding

Box 13 Condition Results

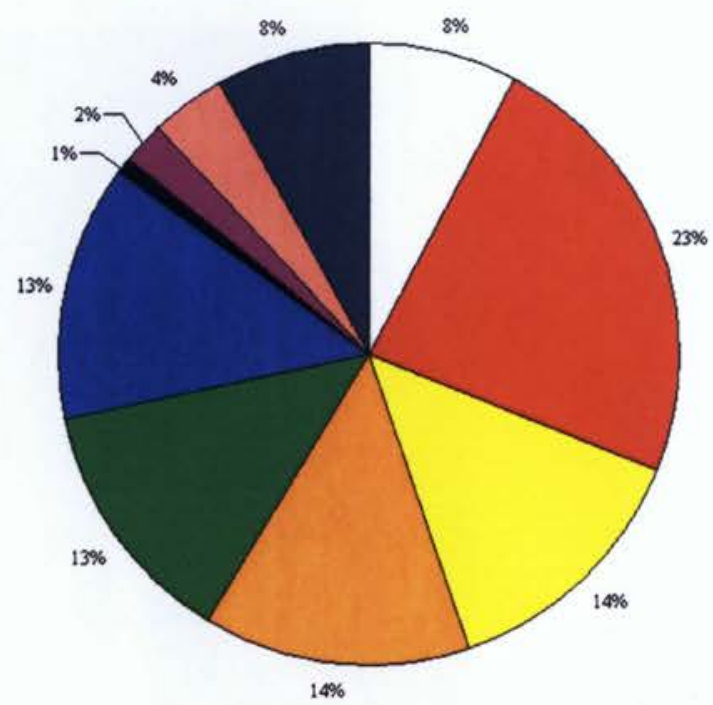

$\square$ Tears/Gouges/Dents

a Abrasion

口 Stains/Foxing

$\square$ Grime/Dirt/Marks

- Silver Mirroring

a Fading

- Mould/Rodent Damage

- Accretion

$\square$ Finger Prints

- Curling/Cockling 


\section{Appendix $\mathrm{H}$}

\section{Chart of Most Common Types of Deterioration Found Throughout the Overall Sample}

Deterioration Found in Overall Condition Report

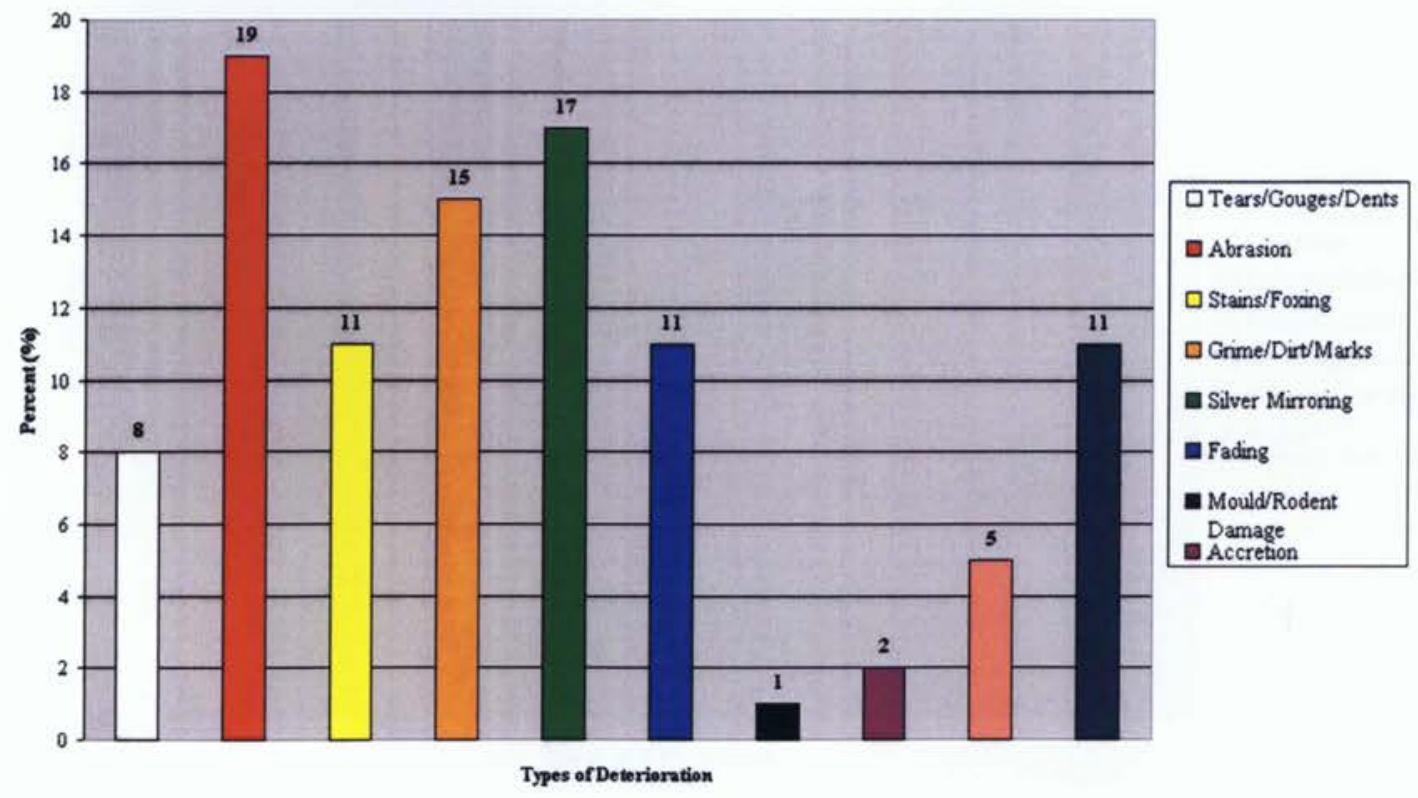




\section{Appendix I}

\section{Chart of Most Common Types of Deterioration Found in the Particulars Sheets}

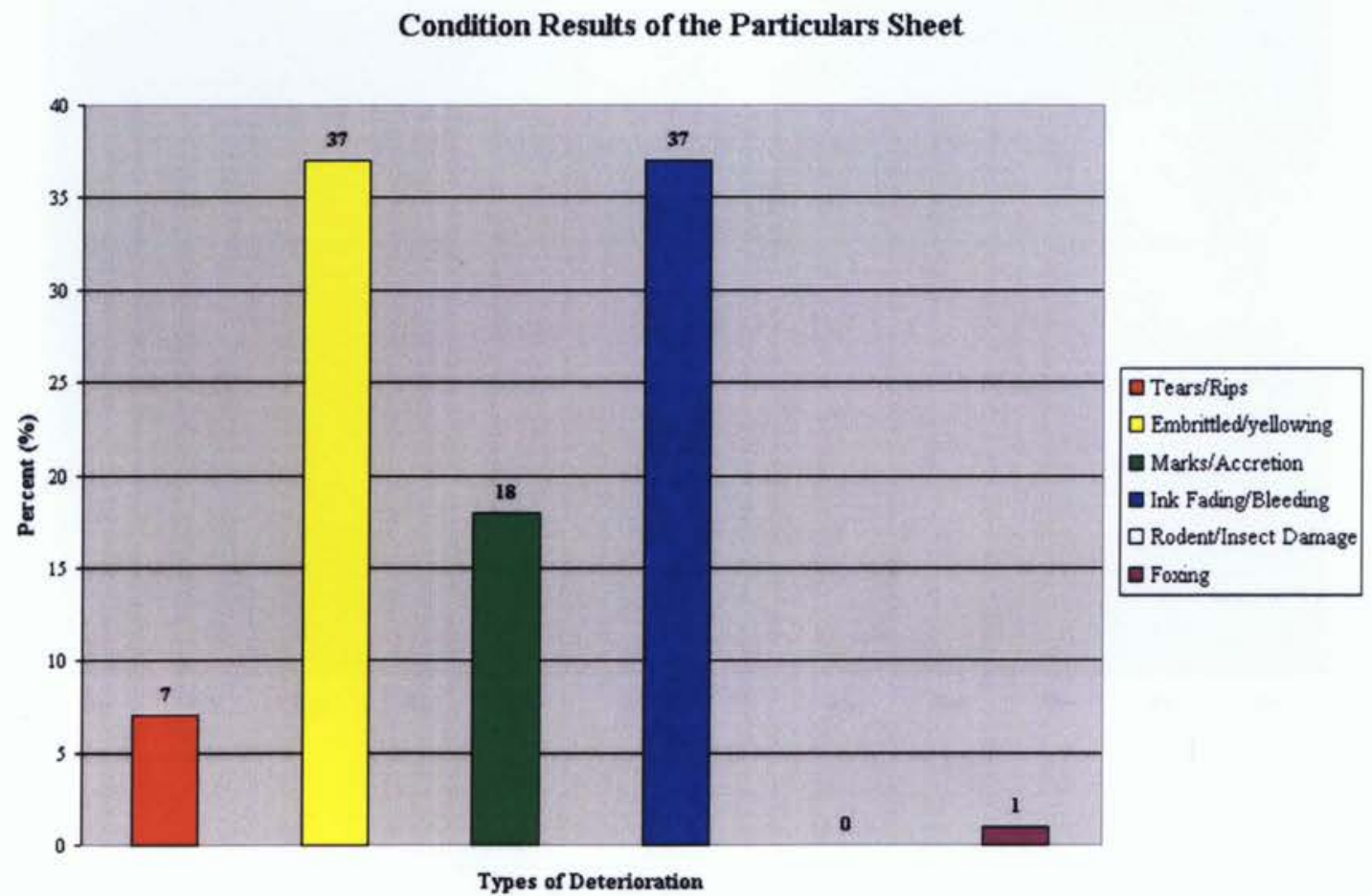




\section{Appendix $\mathrm{J}$}

\section{Environmental Report Charts}

Average Daily Temperature Fluctuations for 2007

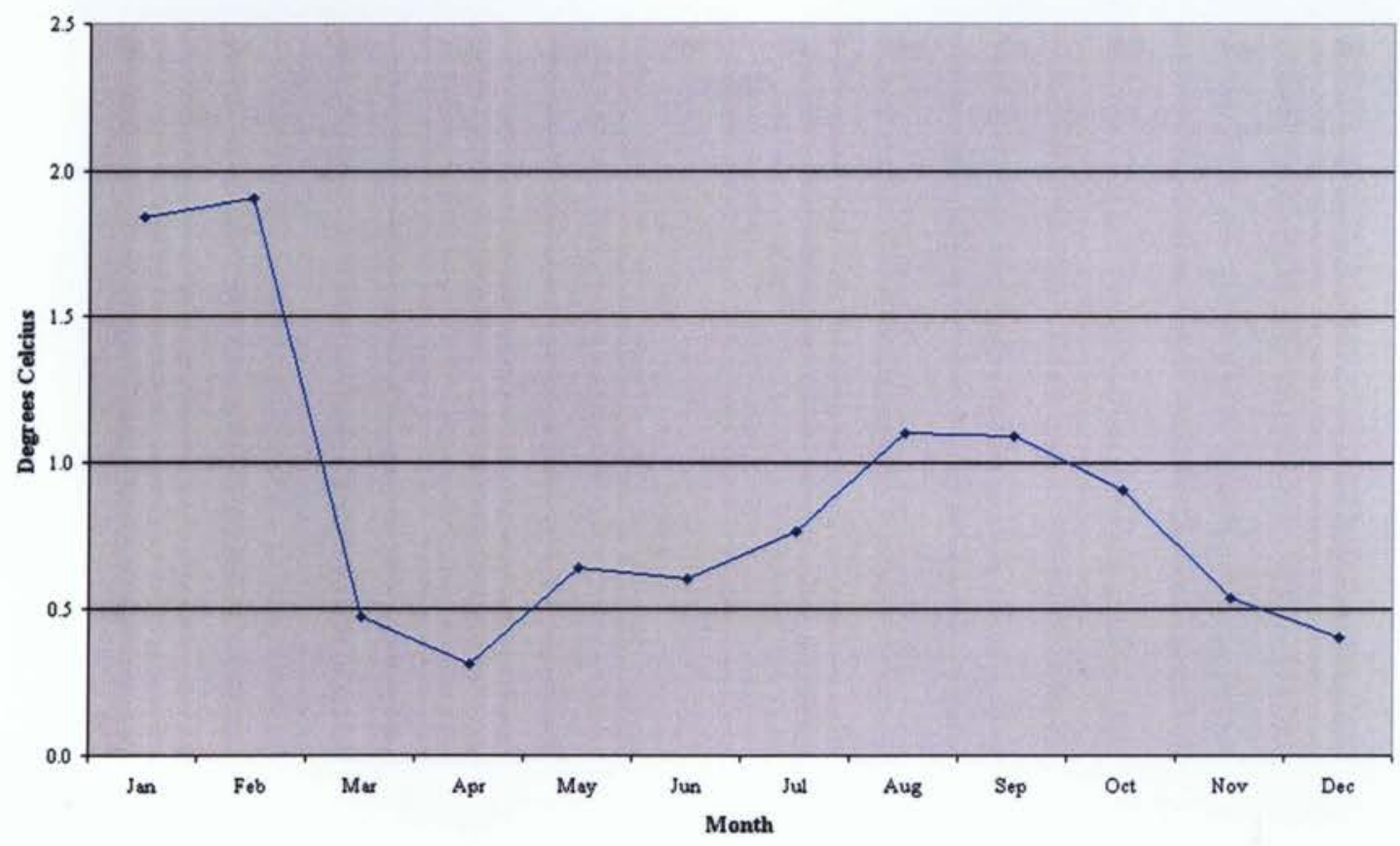


Average Daily Relative Humidity Fluctuations for 2007

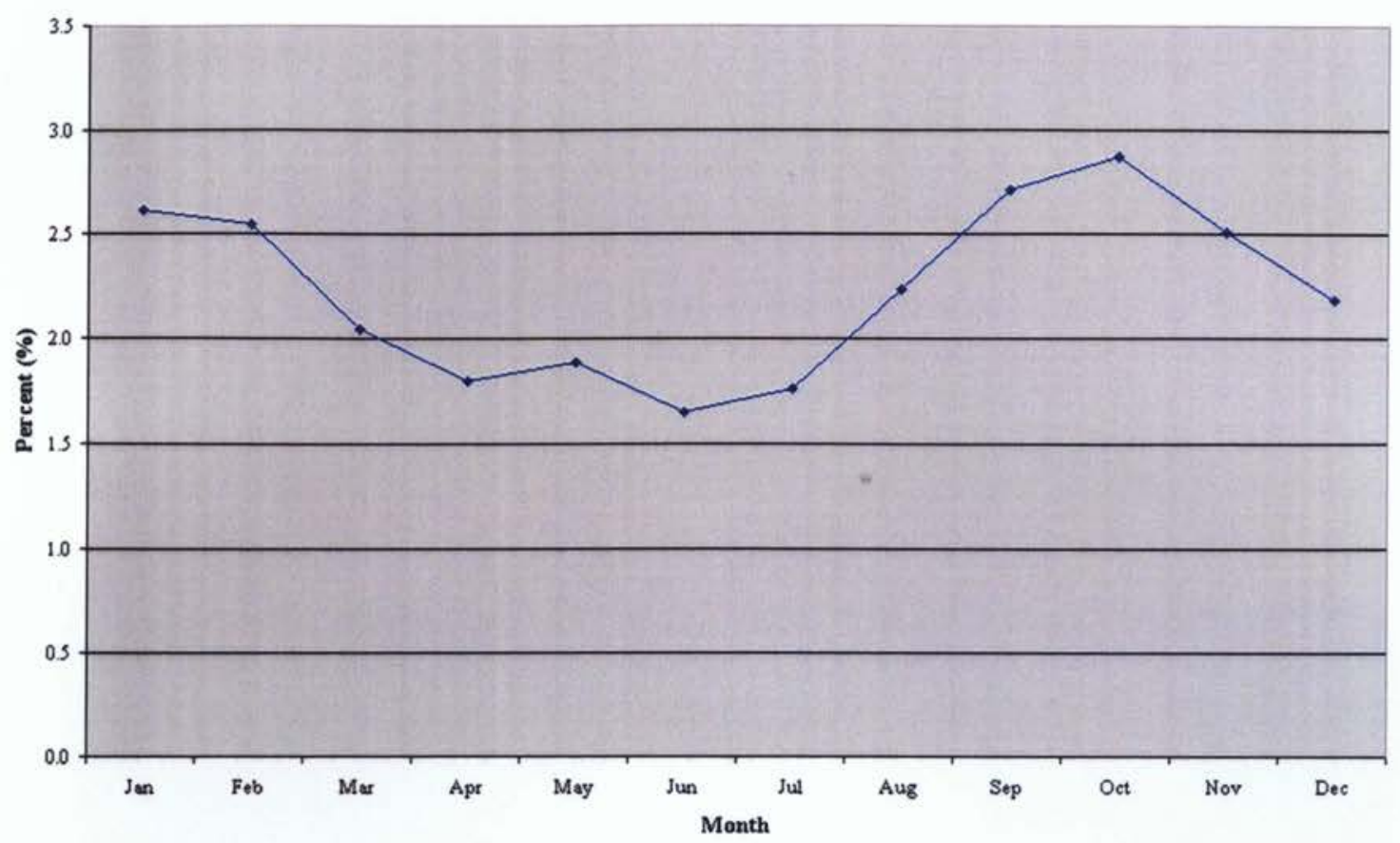

